\title{
LESSONS LEARNED IN FINANCING RAPID RESPONSE TO RECENT EPIDEMICS IN WEST AND CENTRAL AFRICA
}

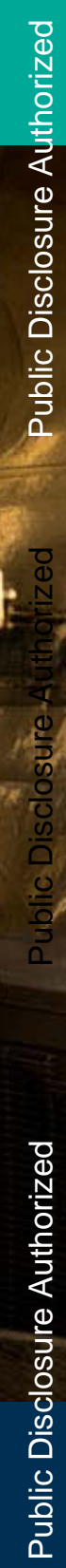

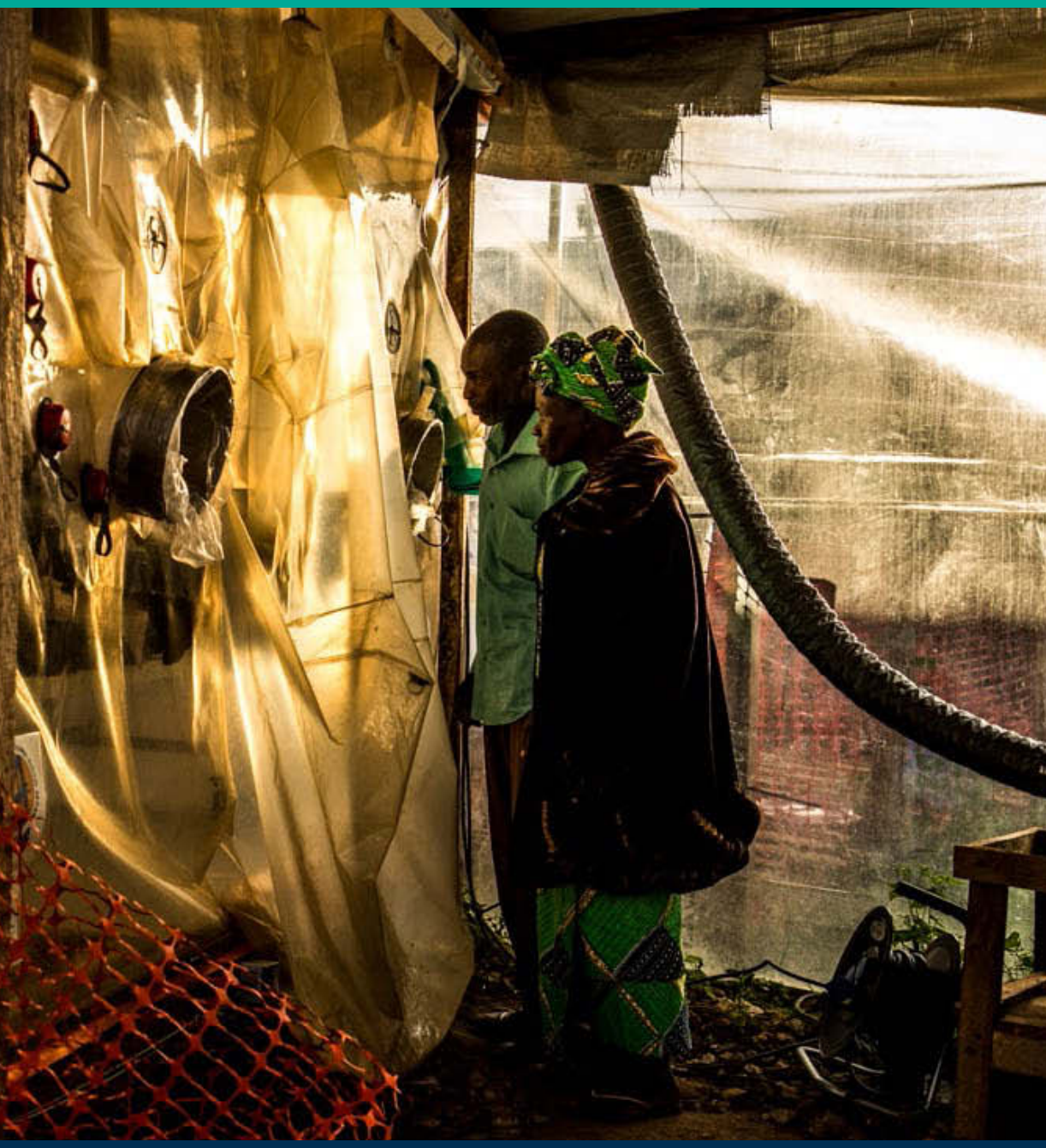

() 2019 The World Bank/Vincent Tremeau 
Cover photo: Vincent Tremeau/World Bank

Abstract: This World Bank Group qualitative study examines whether lessons learned during the financing of the West Africa Ebola crisis of 2014-2015 have resulted in more effective and efficient financing responses from the international development community during more recent disease outbreaks, including in Nigeria (Lassa Fever, 2018) and the 9th outbreak of Ebola in the Democratic Republic of the Congo. The study reflects on positive changes in the affected countries, identifies remaining persistent challenges, and offers recommendations on the way ahead for the consideration of the international development community. 
FINAL REPORT

\title{
LESSONS LEARNED IN FINANCING RAPID RESPONSE TO RECENT EPIDEMICS IN WEST AND CENTRAL AFRICA
}

\author{
May 2019
}





\section{CONTENTS}

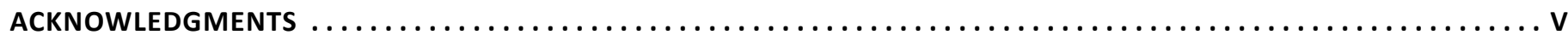

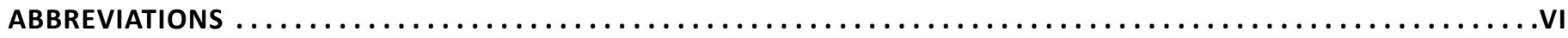

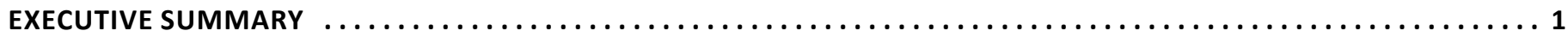

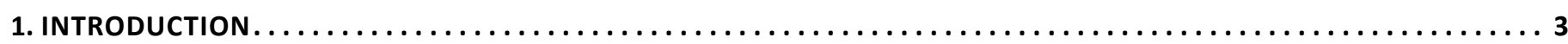

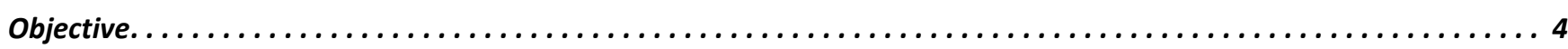

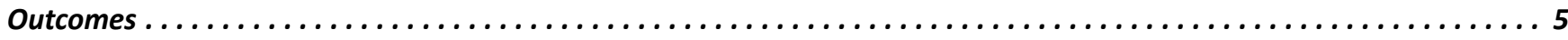

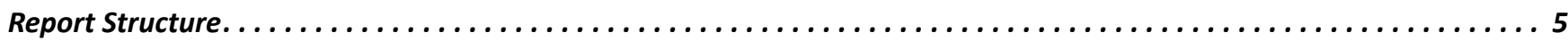

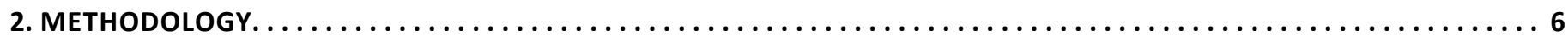

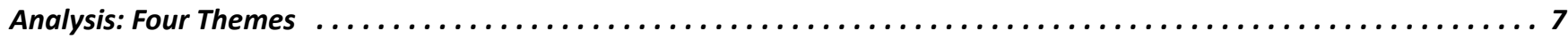

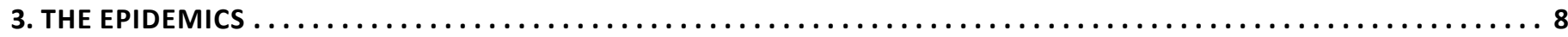

West Africa Ebola Virus Disease (Ebola) in Guinea, liberia, Sierra leone, 2014-2015 $\ldots \ldots \ldots \ldots \ldots \ldots \ldots \ldots .9$

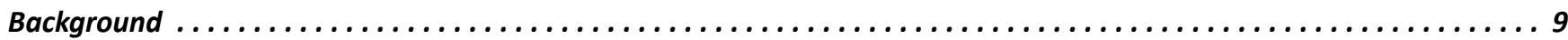

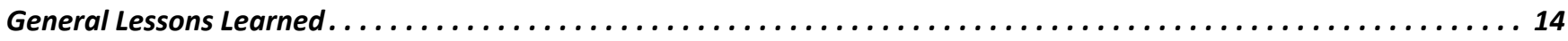

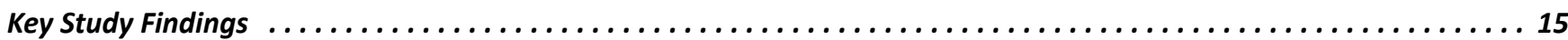

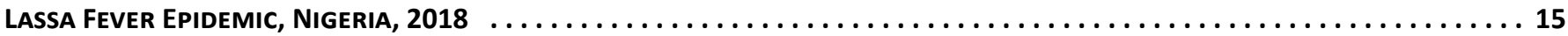

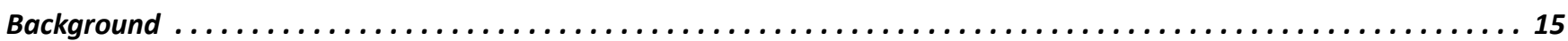

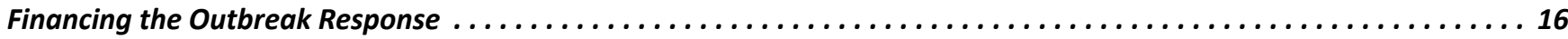

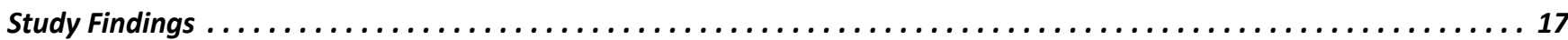

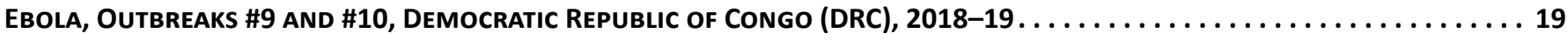

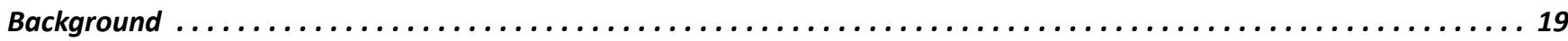

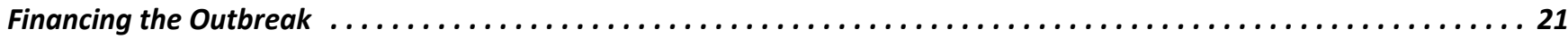

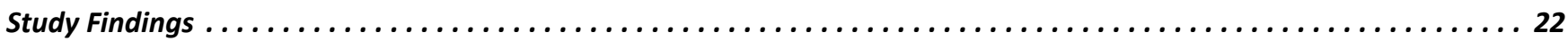

4. WHAT HAS CHANGED IN THE EPIDEMICS OF 2018? CONTINUING CHALLENGES $\ldots \ldots \ldots \ldots \ldots \ldots \ldots \ldots \ldots \ldots$

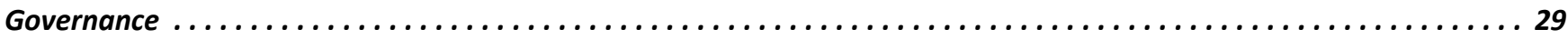

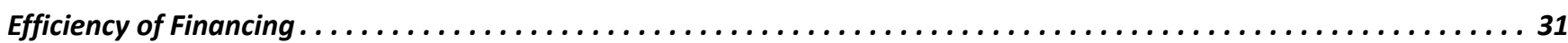

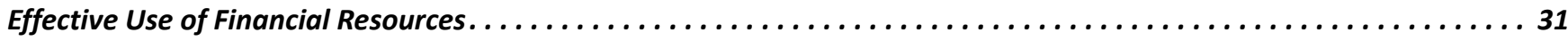

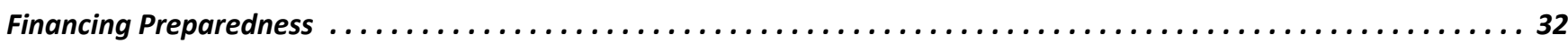

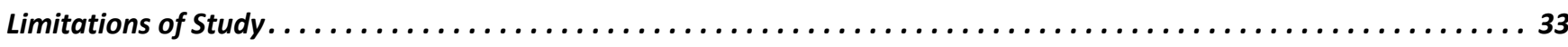

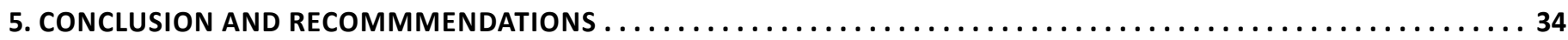

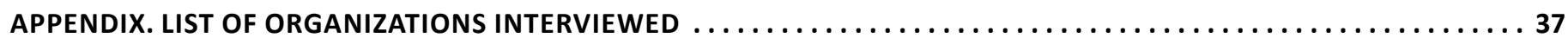

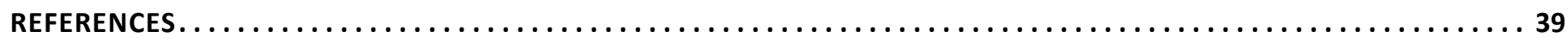




\section{Boxes}

Box 1 Avian Influenza: Missed Opportunity for Preparedness . . . . . . . . . . . . . . . . . . . 13

Box 2 World Bank Ebola Recovery and Reconstruction Trust Fund (ERRTF) . . . . . . . . . . . . . . . 14

Box 3 Regional Disease Surveillance Systems Enhancement (REDISSE) Program . . . . . . . . . . . . . . . 18

Box 4 Impact of Insecurity on Outbreak Detection, Response, and Financing $\ldots \ldots \ldots \ldots$

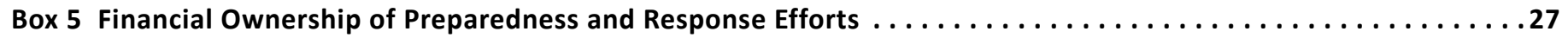

\section{Figures}

Figure 1 West Africa Ebola Outbreaks, 2014-2015: Epidemiological Curve, Key Events, and Funding Commitments

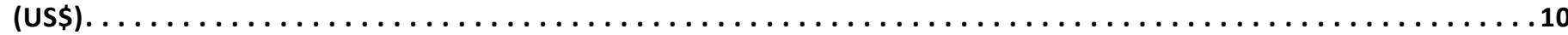

Figure 2 Amount of WA 2014-15 Ebola Financing Disbursed by Donor . . . . . . . . . . . . . . . . . . .12

Figure 3 Nigeria Lassa Outbreak, 2018: Epidemiological Curve, Key Events, and Funding Commitments . . . . . . . . .18

Figure 4 DRC 9th Ebola Outbreak: Epidemiological Curve, Key Events, and Funding Commitments, 2018 . . . . . . . . 19

Figure 5 DRC 10th Ebola Outbreak: Epidemiological Curve, Key Events, and Funding Commitments . . . . . . . . . . . 20

Figure 6 Insecurity and Weak Community Engagement Hindered Ebola 10 Response Efforts, DRC. . . . . . . . . . . 24

Figure 7 Selected Funding Sources during Stages of an Outbreak and Recovery . . . . . . . . . . . . . . . . . 27

Figure 8 "Readiness" Score Based on Joint External Evaluations in Sub-Saharan Africa, 2019 . . . . . . . . . . . . . . . 29

\section{Tables}

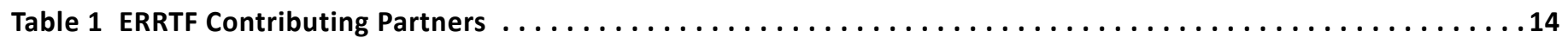
Table 2 Selected World Bank and Other Development Public Health Emergency Financing Tools and Contingency

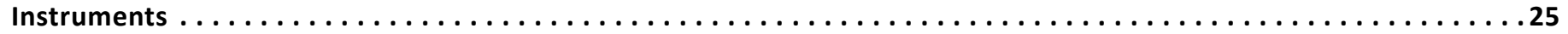

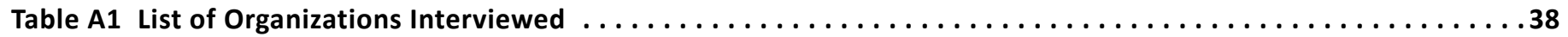




\section{ACKNOWLEDGMENTS}

We would like to extend our appreciation to all the individuals, organizations, and institutions who provided their knowledge and expertise to the development of this report. In particular, we would like to thank the governments of the Democratic Republic of Congo, Guinea, Liberia, Nigeria, and Sierra Leone for graciously giving their valuable time and insights. We would also like to acknowledge the numerous development agencies, international organizations, and nongovernmental organizations who contributed to this work. We are grateful to the World Bank staff in headquarters and country offices who shared their insights and inputs with the team.

Finally, we would like to thank the World Bank Ebola Recovery and Reconstruction Trust Fund for their generous funding which enabled us to document the lessons learned in financing responses to disease outbreaks. We hope that this report contributes to an essential body of work that strengthens our global and local ability to prepare for and manage epidemics.

This report was prepared by Sulzhan Bali, Andre Carletto, John Paul Clark, Sara Hersey, Alicia Hetzner, Hadia Samaha, Nicholas Studzinski, and Mazvita Zanamwe. Olusoji Adeyi, Ivar Cederholm, and Trina Haque provided strategic guidance throughout this project. Fieldwork oversight was provided by Noel Chisaka, Preeti Kudesia, Ibrahim Magazi, Munirat Ogunlayi, Michael Olugbile, and Shiyong Wang. Norosoa Andrianaivo, Karine Noelle Mouketo-Mikolo, and Amba Denise Sangara provided the team with crucial operational and administrative support. The team also benefitted immensely from the peer review provided by Uma Mathur, Adrienne McManus, David Oliveira De Souza, and Netsanet Walelign Workie.

\section{THIS STUDY IS FUNDED BY THE EBOLA RECOVERY AND RECONSTRUCTION TRUST FUND (ERRTF)}

Countries contributing to the ERRTF include:

Russia-Ministry of Finance of the Russian Federation

United Kingdom-Department for International Development (DFID)

Norway-Ministry of Foreign Affairs, Norwegian Agency for Development Cooperation

Netherlands-Ministry of Foreign Affairs

Denmark-Danish Ministry of Foreign Affairs

Japan-Ministry of Foreign Affairs 
AAR

Africa CDC

After Action Review

JICA

LHSSP

LMIC

ALIMA

APL

ARC

AU

CAT DDO

CEPI

CERF

CERC

CFE

CHAI

CRW

DFID

DRC

DRM

ECHO

EERP

ERRTF

EOC

Ebola

FCAS

FGON

GCRP

GDP

$\mathrm{GIZ}$

GPMB

IDA

IFC

GPAI

$\mathrm{HCW}$

HIP

IHR

IMF

IPC

JEE
Africa Centres for Disease Control and Prevention

Alliance for International Medical Action

Adaptable Program Lending

Africa Risk Capacity

African Union

IBRD Catastrophe Deferred Drawdown Option

Coalition for Epidemic Preparedness

Innovations

Central Emergency Response Fund

Contingent Emergency Response Component

WHO Contingency Fund for Emergencies

Clinton Health Access Initiative

World Bank IDA Crisis Response Window

United Kingdom-Department for

International Development

Democratic Republic of Congo

Disaster Risk Management

European Commission's Humanitarian Aid

and Civil Protection department

Ebola Emergency Response Project

Ebola Recovery and Reconstruction Trust

Fund

Emergency Operations Center

Ebola Virus Disease

Fragile and Conflict-Affected Situations

Federal Government of Nigeria

Global Crisis Risk Platform

Gross Domestic Product

Deutsche Gesellschaft für Internationale Zusammenarbeit

Global Preparedness Monitoring Board

International Development Association

International Finance Corporation

Global Pandemic and Avian Influenza

Health care workers

Humanitarian Implementation Plan

International Health Regulations

International Monetary Fund

Infection Prevention and Control

Joint External Evaluations
$M \& E$

MIGA

MDTF

MERS

MOF

$\mathrm{MOH}$

MSF

MOU

NAPHS

NCDC

OIE

PEF

PDSS

RCC

REDISSE

RVF

SARS

SLRCHP

SRP

UN

UNFPA

UNICEF

UNMEER

UN MPTF

UNOCHA

UNOPS

USA

WAHO

WBG

WHA

WHE

WHO
Japanese International Cooperation Agency

Liberia Health Systems Strengthening Project

Lower- and Middle-Income Countries

Monitoring and Evaluation

Multilateral Investment Guarantee Agency

Multi-Donor Trust Fund

Middle East Respiratory Syndrome-Related

Coronavirus

Ministry of Finance

Ministry of Health

Médecins Sans Frontières

Memorandum of Understanding

National Action Plans for Health Security

Nigeria Centre for Disease Control

World Animal Health Organization

Pandemic Emergency Financing Facility

DRC Health System Strengthening for Better Maternal and Child Health Results Project

Regional Coordinating Center

Regional Disease Surveillance Systems

Enhancement

Rift Valley Fever

Sever Acute Respiratory Syndrome

Sierra Leone Reproductive and Child Health Project

Strategic Response Plan

United Nations

United Nations Population Fund

United Nations Children's Fund

United Nations Mission for Ebola Emergency

Response

United Nations Multi-Partner Trust Fund

United Nations Office for the Coordination of Humanitarian Affairs

United Nations Office for Project Services

Unites States of America

West African Health Organization

World Bank Group

World Health Assembly

World Health Organization Health

Emergencies Program

World Health Organization 
When the Ebola Virus Disease (Ebola) struck Guinea, Liberia, and Sierra Leone in 2014, the affected countries and the international community were poorly equipped to provide a timely financial and technical response to contain the regional epidemic. Lack of adequate disease surveillance and response systems hampered detection of the Ebola outbreak in all three countries. As a result over 11,000 persons died and although the populations of the three most affected countries suffered the bulk of the direct and indirect costs of the epidemic, there were significant health, social, and economic consequences across the subregion. The economic and social costs of the West Africa Ebola crisis were recently estimated at US\$53 billion (Huber, Finelli, and Stevens 2018).

Although delayed by several months from the onset of cases, the global response eventually was effective in stopping the outbreak. The response ultimately mobilized over US\$5.91 billion by February 2015 and started a chain of organizational, strategic, and financial reforms that continue.

While there is a significant body of work examining lessons from the 2014-15 Ebola outbreak in West Africa (201415 WA Ebola), there is limited literature on how those lessons have been applied to successive epidemics in the subregion, particularly on the financing of outbreak response. This report examines the extent to which these lessons have changed institutional behavior and contributed to improved domestic and international coordination of subsequent disease outbreaks in the region. Specifically, it highlights how these lessons have been applied to the 2018 Lassa Fever outbreak in Nigeria, the 9th Ebola outbreak in the Democratic Republic of Congo (DRC), and the ongoing 10th Ebola outbreak in DRC.

The report illustrates the unique challenges posed in financing each outbreak, identifies best practices that have been established, and underscores the obstacles and challenges that remain. The findings will guide policy decisions and help inform domestic and international institutions on the challenges that remain in financing emergency response to epidemics.

Lessons learned from the West Africa Ebola outbreak have benefitted subsequent outbreaks, including the 2018 Lassa Fever epidemic in Nigeria and the 2018 and 2019 Ebola outbreaks in DRC. The study found strong consensus among informants that the financial response to these outbreaks is markedly improved compared to that of the 2014-15 Ebola outbreak in West Africa.
- In response to comprehensive recommendations from multiple assessments, the international development community has taken several institutional and operational steps to improve the efficiency and effectiveness of financing public health emergencies. These include the adaptation of policies and procedures that increase the agility of financing while decreasing the processing time, as well as developing new planning tools and financing mechanisms. Some examples include incorporating instruments that permit rapid access to funds into World Bank-financed projects and establishing new financing mechanisms such as the World Bank Group (WBG)'s Pandemic Emergency Financing Facility (PEF), World Health Organization (WHO)'s Contingency Fund for Emergencies (CFE), and the African Union (AU)'s Africa Risk Capacity (ARC) for Outbreaks. There have also been efforts to establish and strengthen institutions with global, regional, and national mandates for preparedness and response, such as the WHO Health Emergencies Program (WHE), Africa Centres for Disease Control and Prevention (Africa $\mathrm{CDC}$ ), and National Public Health Institutes (NPHIs).

- Although financing routine systems to prevent and detect health threats has lagged behind initiatives to respond to emergencies, new disease surveillance and response programs have been introduced in the African subregion. One such example is the WBG's Regional Disease Surveillance Systems Enhancement (REDISSE) Program, which leverages efficiency gains of scale by strengthening disease surveillance, detection, and response systems across 11 countries in West Africa.

- In addition to delayed disease detection and resource mobilization, the 2014-15 WA Ebola outbreak was hindered by weak coordination and accountability including lack of systems to accurately track funding, which further delayed disbursements. It took approximately two months before funds were available for WHO due to complex financial controls. WBG pledged funds within five days of the first emergency declaration in Sierra Leone on July 31, 2014. However, it took WBG 
nearly two months ${ }^{1}$ to secure and disburse the funds. The regional outbreak lasted over one and a half years and the response ultimately cost US\$6 billion. Early access to flexible funds, even in small amounts, would have mitigated many of the adverse health consequences of the outbreak. (WHO, 2015a).

- In contrast to the 2014-15 Ebola outbreak, the response to the 2018 Lassa Fever outbreak exhibited more efficient coordination and improved timeliness in resource mobilization. Leadership capacity of the Nigeria Center for Disease Control (NCDC), establishing the Lassa Fever Technical Working Group (TWG), and the use of CFE and Contingent Emergency Response Component (CERC) mechanisms facilitated these improvements. However, CERC activation was set back by more than two weeks due to complex interministerial processes and lack of prepositioned response tools. Contracts and disbursements were also delayed while staff were familiarized with the new funding mechanism.

- The 9th Ebola outbreak in DRC benefitted from the presence of an existing World Bank disease surveillance project that enabled immediate procurement using previously allocated funds. Funding for the response was mobilized in less than one week through a number of modalities including the PEF cash window, CERC, and CFE. The Strategic Response Plan (SRP) also greatly improved government and development partner coordination. Funds that were not used to respond to this outbreak were applied to the 10th Ebola outbreak in DRC, which was declared shortly after the end of the 9th outbreak.

- In contrast to the 9th Ebola outbreak in DRC, the 10th outbreak occurred in an area of ongoing insecurity. The outbreak was confirmed nearly three months after the first community deaths due to frequent health worker strikes and lack of health facility access. Despite rapid initial resource mobilization and extensive national and international efforts to interrupt disease transmission, many challenges impede resolving the outbreak. These include community mistrust, an increasingly insecure environment for response workers, and difficulty in coordinating multiple response actors. At the time of this report, the

${ }^{1}$ In Sierra Leone, the emergency was declared on July 31, 2014. The World Bank Ebola Emergency Response Project (EERP) was declared effective on September 19, 2014, and it became effective in Sierra Leone on September 24, 2014. 10th Ebola outbreak in DRC was the second largest Ebola outbreak to date. With a protracted response, donor fatigue remains a risk that could also hamper financing of the epidemic response going forward.

This report confirms improvements in the timeliness and efficiency of financing to contain outbreaks of infectious disease at all levels-country, regional, and global. Today, Guinea, Liberia, Sierra Leone, Nigeria (Lassa Fever outbreak, 2018), and the Democratic Republic of Congo (DRC) (9th and 10th outbreaks of Ebola) have demonstrated improved capacity for governance and operational response to outbreaks. This capacity growth, in turn, has contributed to the more efficient use of domestic and external financing.

However, many challenges remain. The capacity of highrisk countries to address public health emergencies will be difficult to sustain without a shared, continued commitment of both domestic and external financing. International development and public health agencies such as the World Bank and WHO have also demonstrated significantly greater agility in their institutional responses due, in part, to the development of a number of new and improved funding instruments and planning tools that enable more timely and flexible financing of outbreaks. Other national and regional entities including NPHIs and the Africa CDC are also poised to provide increased indigenous support as their institutions mature.

Adequate domestic investment in outbreak prevention and preparedness remains a critical challenge. The barriers to such investment stem from a combination of scarce resources and competition across sectors in prioritizing the resources available. Following the West Africa Ebola outbreak, although international investments have proved adequate to address acute outbreak needs, funding for preparedness has severely waned.

Given its financing mandate, convening authority, and access to economic/financial policy decision makers, the World Bank is well positioned to lead a scaled-up, multistakeholder initiative on innovative financing to strengthen country-owned and country-led capacity for preparedness. In the context of the demonstrated importance of global health security, the time is also opportune for international development partners to systematically examine their overall strategies. These strategies encompass the flexibility, agility, and efficiency of existing financing tools for emergency response and building country-owned capacity for financing preparedness and emergency response. 


\section{INTRODUCTION}
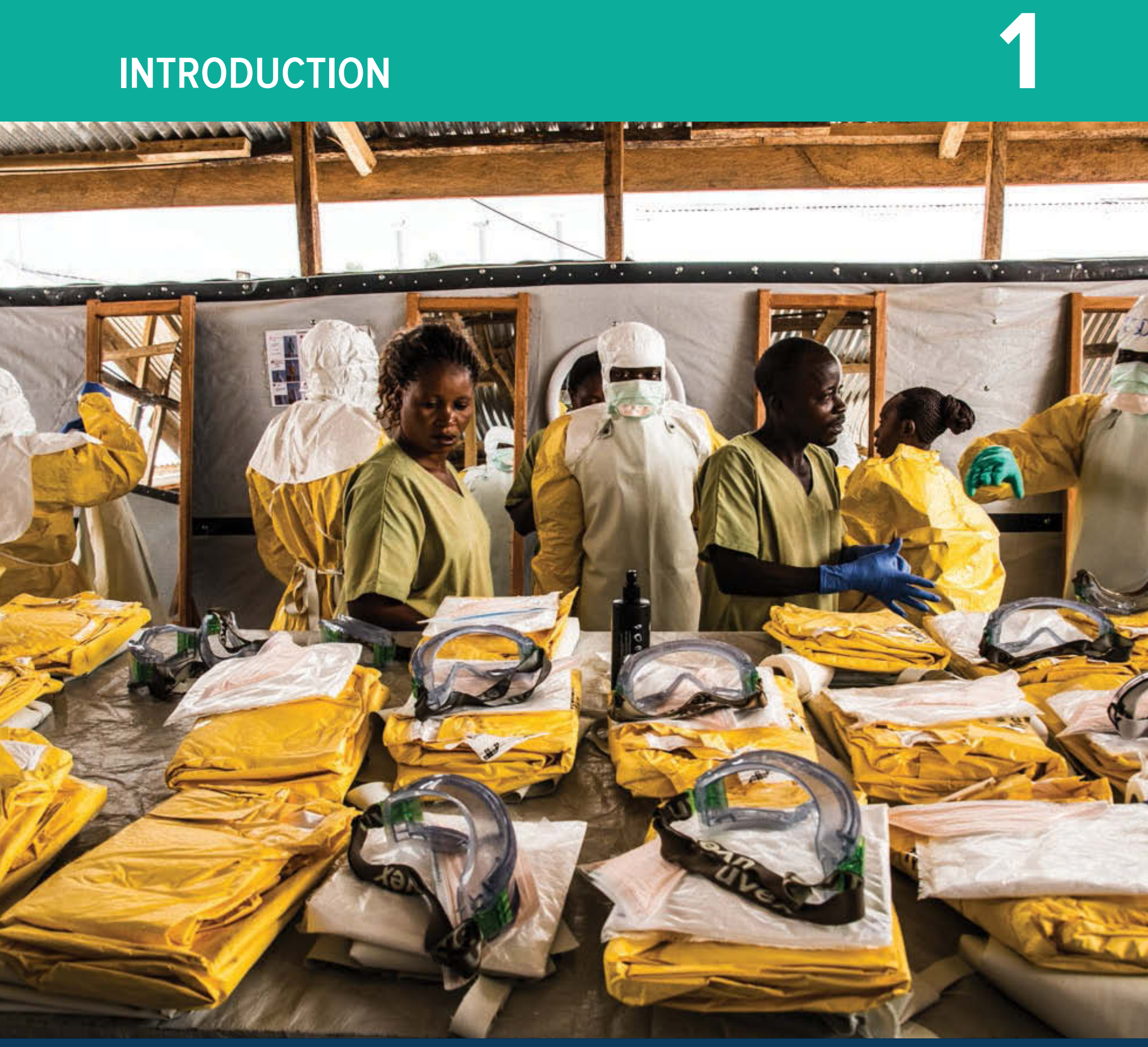

두 2019 The World Bank/Vincent Tremeau 
In the wake of the 2014 Ebola Virus Disease (Ebola) crisis, the international development community, including the World Bank Group (WBG), have taken various institutional and operational steps to improve the advice, investments, and financing instruments to support both the efficiency and effectiveness of emergency responses to infectious disease outbreaks. Several World Bank instruments have been developed or adapted to more promptly deliver financial resources. These instruments include a Contingent Emergency Response Component (CERC) which permits rapid access to funds in existing bank-financed projects; the Catastrophe Deferred Drawdown Option (Cat DDO) which is newly available to the International Development Association (IDA) eligible countries and functions as a contingency fund; and the Pandemic Emergency Financing Facility (PEF), with its parametric insurance and cash windows. Other international stakeholders and donors, including the World Health Organization (WHO), African Union (AU), and United Nations Office for the Coordination of Humanitarian Affairs (UNOCHA), have developed new or improved rapid response instruments. These include WHO Contingency Fund for Emergencies (CFE); Africa Risk Capacity (ARC), an insurance-based financing scheme; and a modified Central Emergency Response Fund (CERF) for health emergencies for the respective organizations.

Additionally, multiple institutions have moved to strengthen regional and international capacity to respond to disease outbreaks. Two examples are the establishment of the (1) Health Emergencies Program (WHE) by WHO and (2) Africa Centres for Disease Control and Prevention (Africa CDC) by the African Union. The adoption of the Global Health Security Agenda (GHSA) by over 50 countries and the implementation of Joint External Evaluations (JEEs) in more than 85 countries have resulted in higher quality and more transparent implementation and monitoring of country progress toward WHO International Health Regulations (IHR-2005). WHO, the World Bank, and other stakeholders recently established the Global Preparedness Monitoring Board (GPMB) to provide oversight of international health security efforts. Although financing for the strengthening of routine systems to prevent and detect health threats has lagged behind initiatives to respond to emergencies, new regional disease surveillance and response programs have been introduced in Africa such as the World Bank Regional Disease Surveillance Systems Enhancement (REDISSE) Program.
This report assesses if and how these new instruments, investments, and changes in institutional behavior are improving the timeliness, sufficiency, and effectiveness of financing for recent and ongoing epidemics in the Africa region, specifically the 2018 Lassa Fever outbreak in Nigeria and the 9th and 10th Ebola outbreaks in the Democratic Republic of Congo (DRC). The study illustrates how each new outbreak poses unique challenges, while underscoring the persistence of common obstacles and weaknesses. It will identify good and best practices that have been adopted based on recent experience and examine the unresolved gaps and weaknesses in systems capacity and resilience to epidemic outbreaks at country and local levels in the Africa Region (AFR) as well as in the regional and global contexts. Three years after the end of the West African Ebola epidemic, this study will explore:

How well have the lessons from the West Africa Ebola crisis of 2014-15 on the financing of epidemic response been documented and applied to subsequent outbreaks? What additional lessons have we learned from these more recent outbreaks in Nigeria and DRC? and What have we still to learn?

\section{OBJECTIVE}

The objective of the study is to inform the design and implementation of financing for rapid response to outbreaks through an analysis of lessons learned from recent outbreaks in West and Central Africa. The study aimed to:

1. Document the institutional steps and progress made by development partners, including the WBG, to adapt, develop, and implement financing tools to respond to disease outbreaks and other public health emergencies.

2. Identify the lessons learned from financing the immediate response to recent outbreaks in West and Central Africa, specifically, the 2014-15 Ebola outbreak in West Africa, the 2018 Lassa Fever outbreak in Nigeria, and 9th and 10th Ebola outbreaks in the DRC in 2018.

3. Document the principal barriers and enablers to external and domestic financing for rapid response to epidemics. Documentation focuses on efficiency (including timeliness and flexibility), sufficiency (resource mobilization and disbursement), and effectiveness of coordination and use of funds. 
4. Provide key recommendations on how to accelerate external and domestic financing and operationalization of response to future disease outbreaks.

\section{OUTCOMES}

The primary outcomes of this study are to (1) inform stakeholders, including development partners and countries, of lessons learned in financing responses to recent epidemics in the West and Central Africa regions; and (2) increase the knowledge resources at the country, regional, and global levels on expeditious financing of responses to infectious disease outbreaks.

\section{REPORT STRUCTURE}

This report will explain the methodology used to collect and analyze study data. It will then review the background, findings, and observations on mobilizing domestic and external funds for response in light of the evolution of epidemics in West Africa (Ebola, 2014-15), Nigeria (Lassa Fever, 2018), and DRC (Ebola, 2018-2019). The following section will summarize the recent changes and key remaining challenges globally and in select countries summarized by the four selected themes (Governance, Effective Financing, Efficient Use of Resources, and Preparedness). The report then will offer conclusions and recommendations from this qualitative study. 


\section{METHODOLOGY}

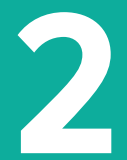

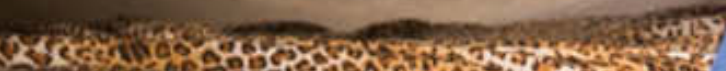

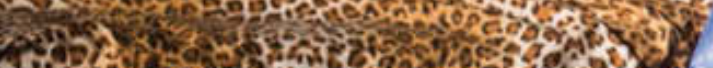

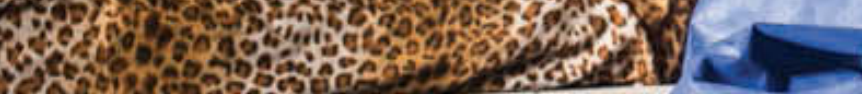

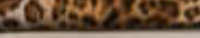

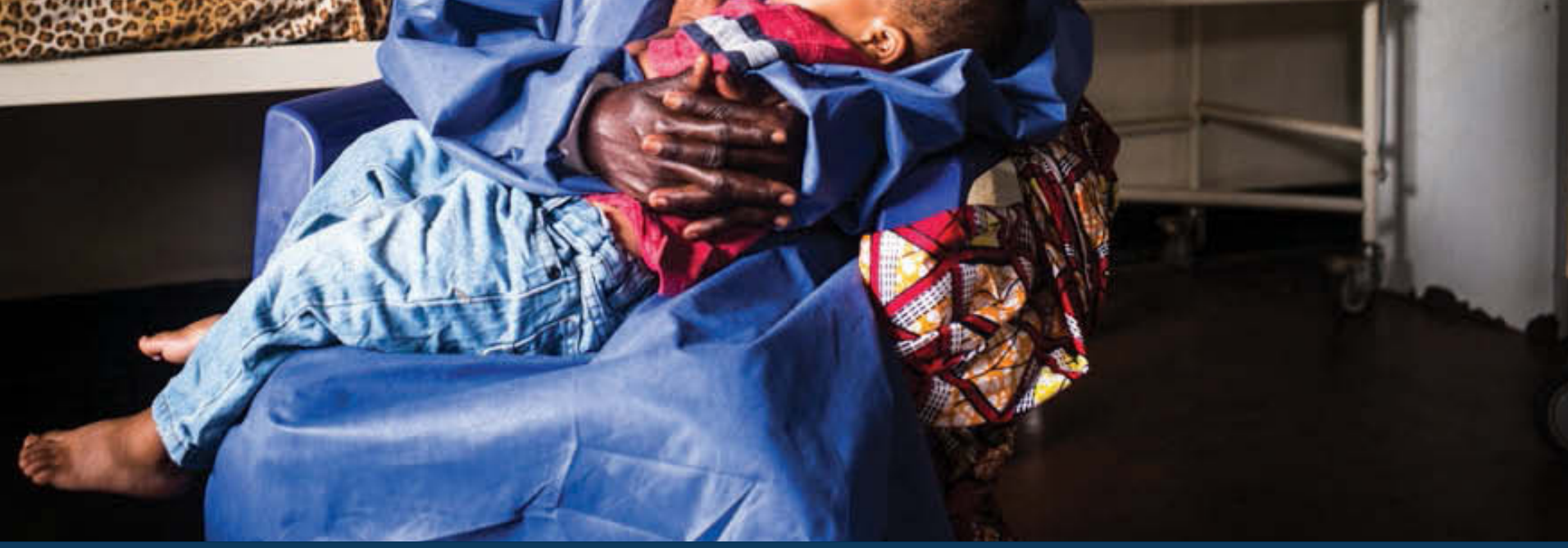

ㄷ 2019 The World Bank/Vincent Tremeau 
This study was designed as a cross-sectional qualitative study. To capture the lessons learned from financing rapid response to recent outbreaks in West and Central Africa, the study employed semi structured, in-depth interviews complemented by an exhaustive review of the published literature and unpublished documentation. The data were collected in Conakry, Guinea; Monrovia, Liberia; Abuja, Nigeria; Freetown, Sierra Leone; Geneva, Switzerland; London, UK; and Washington, DC, USA. Purposive sampling was used to create the researcher's guide to key stakeholder organizations and names. The list was cross-checked with key informants, and 138 persons $^{2}$ were interviewed during both phases. The in-depth interviews were conducted in English or French and lasted 45-75 minutes each. The interviews were conducted primarily face to face; a small number were conducted by video or audio conference.

Coding was used to analyze the data, and the data were interpreted continuously throughout the coding process to identify key themes and subthemes. Audio recordings of the interviews were transcribed, and the text was analyzed using a two-step approach. Primary coding was performed using Microsoft Word. Analytic memos were written to summarize and organize the data into major themes by combining the initial coding insights for each outbreak. Key themes emerged from the data and, where appropriate, were supplemented with the literature review.

The preliminary report was shared with select key informants and stakeholders in November and December 2018 to validate observations and identify priority issues for further investigation. A second round of interviews and data collection were conducted in the first quarter of 2019.

\section{ANALYSIS: FOUR THEMES}

Three questionnaire instruments were developed. Each instrument contained questions tailored to a specific category of informant: World Bank staff (Senior, HQ level; Task Team

${ }^{2}$ Key informants from WBG (18), government (52), international organizations (31), bilateral donors (14), and nongovernmental organizations (NGOs) (23) participated in the in-depth interviews and focus group discussions.
Leader; Field Project Manager); country government officials; and international development partners including financing, technical, and implementing organizations (multilateral, bilateral, or NGO). The question categories included the process of resource mobilization; the timeliness, flexibility and sufficiency of financial resources; and the effectiveness of coordination and use of funds.

Document and interview-derived data were analyzed, and codes were collated into four high-level themes. Findings on lessons learned were categorized according to these themes. Although some findings were cross-cutting and spanned multiple categories, ${ }^{3}$ they were placed where they were most relevant to the context. The themes are described below:

1. Governance-Management of the response including coordination, planning, leadership, and decision making; collaboration and information sharing between stakeholders.

2. Efficiency of financing for outbreak responseResource mobilization and transfer of authorized funding to the recipient (government or implementing organization) using streamlined procedures; timeliness, agility, and sufficiency of financing based gaps identified in strategic plans.

3. Effective use of financial resources in outbreak response-Financial commitments met their predetermined objectives and were not misused or wasted; absorptive capacity, accountability, monitoring and evaluation of emergency financing, procedures for reporting, and allocative efficiency. ${ }^{4}$

4. Financing for preparedness-Prevention and early detection of disease outbreaks.
${ }^{3}$ For example, fiduciary procedures were relevant to both efficiency of financing and effective use of financing.

${ }^{4}$ Qualitative assessment of whether financing met prioritized local needs, improved local ownership, and was cost effective. 


\section{West Africa Ebola Virus Disease (EBOLA) in GUINEA, LIBERIA, SIERRA LEONE, 2014-2015}

"The money came out plenty, but late."

Delayed resource mobilization, insufficient immediate response, inefficient coordination, delayed disbursement

\section{BACKGROUND}

The West African (WA) Ebola epidemic began in Guinea in early 2014 and was remarkable for its unprecedented spread, which exceeded all other recorded outbreaks of Ebola. The disease was transmitted intensively throughout the West African countries of Guinea, Liberia, and Sierra Leone, and eventually included a minimal and more rapidly controlled spread to seven other countries in West Africa, Europe, and the United States. There have been multiple studies in peer reviewed and gray literature documenting the impact and lessons learned from the outbreak. For this study, an extensive literature review was conducted, and key themes and findings identified were documented.

Effects/Impact of the 2014-15 WA Ebola outbreak. The direct human and indirect socioeconomic impacts among the countries most affected by the epidemic were severe. The outbreak infected over 28,000 people, and the combined deaths included over 11,000 persons (WHO 2016). Economic losses included investments, agricultural production, and food security, and the diminished growth of the private sector. ${ }^{5}$ The human and socioeconomic impacts of the epidemic were large and severe in all three of the countries most affected. Economic losses also included deferred investments, diminished agricultural production and food security, and the diminished growth of the private sector.

There were additional pronounced direct and indirect impacts on the health care, education, and social protection system of the affected countries. These impacts included the complete disruption in the delivery of health, education, and social services. These disruptions caused disastrous effects on vulnerable populations, particularly children and the elderly. In Liberia, 8 percent of health care professionals died; Sierra Leone lost 7 percent, and Guinea 1 percent (Evans and others

${ }^{5}$ Losses were US\$600 million for Guinea, US\$300 million for Liberia, and US\$1.9 billion for Sierra Leone.
2015). Due to (1) the reduction of both demand for and availability of general health services resulting from fear of contracting Ebola; (2) lack of access to health care during the crisis; and (3) the absence of staff and supplies, as many as 10,600 excess deaths were attributed to untreated HIV, tuberculosis (TB), and malaria (Parpia and others 2016). Diverted resources, closed health facilities, and fear of Ebola transmission in health facilities further broke down trust in the health systems in the Ebola-affected countries (Elston and others 2017).

In the three countries combined, an estimated 17,300 children were orphaned; students lost 33-39 weeks of schooling; and child vaccinations decreased by 30 percent (CDC 2016). The combined economic costs in Guinea, Liberia, and Sierra Leone are estimated at US\$53 billion, including the social costs of deaths and morbidity from Ebola and other diseases during the epidemic (Huber and others 2018). A World Bank study found that Ebola in West Africa resulted in a US\$2.2 billion loss in Gross Domestic Product (GDP) for the three Ebola-affected countries, and that the medium-term impact may have caused economic losses of up to US\$25 billion for West Africa (World Bank 2015b).

Outbreak timeline and response. Deaths from Ebola may have occurred as early as December 23, 2013. However, Ebola was not confirmed until March 27, March 30, and May 24, 2014 in Guinea, Liberia, and Sierra Leone, respectively (Figure 1) (Global Ebola Response 2019; CDC 2015). A state of emergency due to the outbreak was first declared in Guinea on August 6, 2014, 131 days after confirmation of the first case; in Liberia on August 13, 136 days after confirmation; and in Sierra Leone on July 31, 67 days after the first case was confirmed. WHO declared an Ebola public health emergency of international concern on August 8. The United Nations (UN) outbreak coordinating body, UN Mission for Ebola Emergency Response (UNMEER), was constituted on September 19. Declarations of the end of the country-specific outbreaks were announced 14-18 months later: May 9, 2015 in Liberia, November 7 in Sierra Leone, and December 29 in Guinea.

Late detection of Ebola coupled with delayed outbreak declarations hampered the international response efforts to trigger emergency financing mechanisms (DuBois and others 2015; Lupel and Snyder 2017; Moon and others 2015; Spengler and others 2016; WHO 2015a; WHO 2015b). The delayed detection and declaration resulted in a lag of approximately 


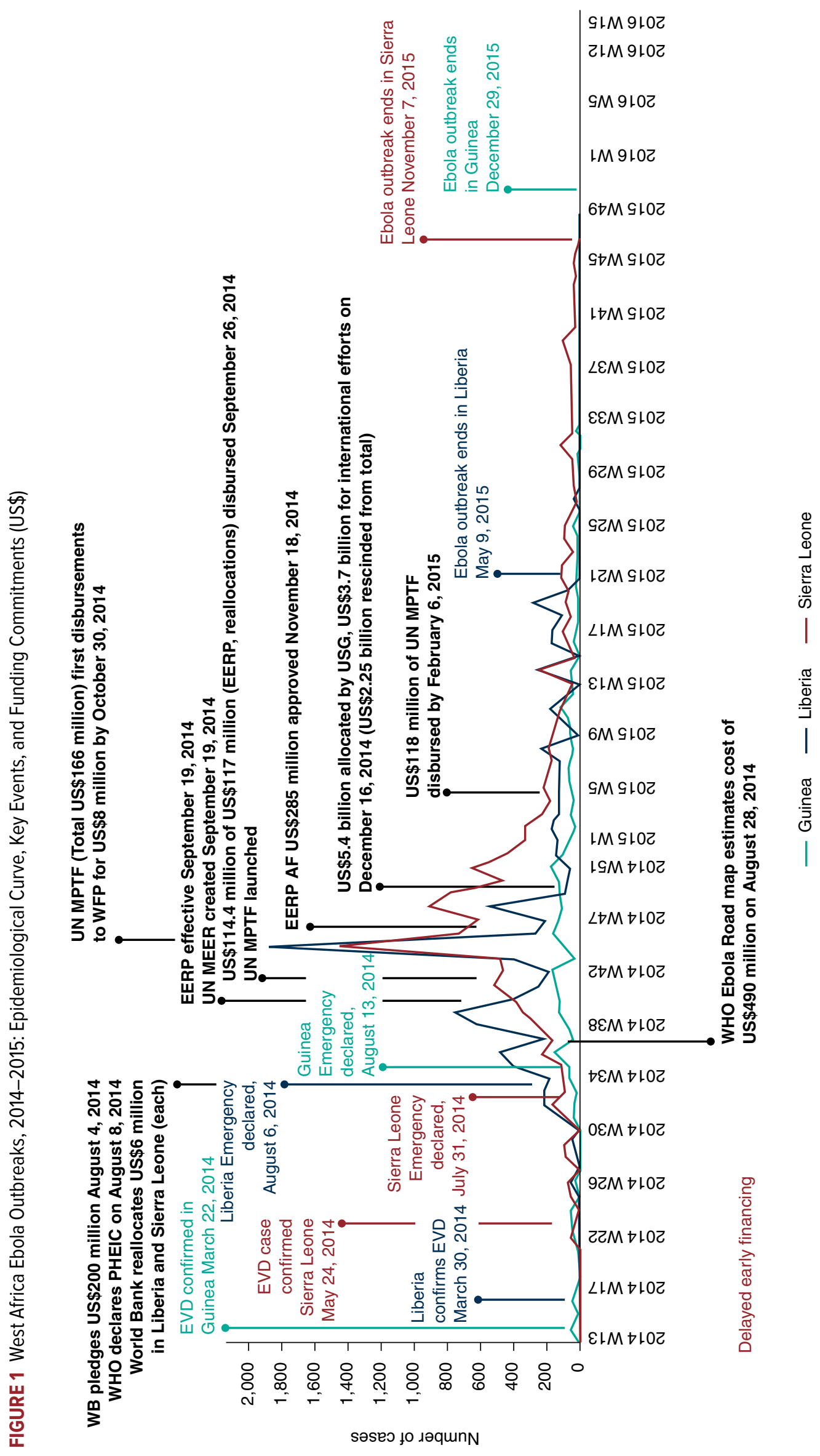


five months ${ }^{6}$ for the international community to declare an emergency and to develop a coordinated and funded containment response appropriate to the severity of the outbreak.

Because several generations of transmission had occurred prior to detection, it was difficult to quantify the magnitude of the outbreak with any accuracy or the funding required to contain it. One study highlights how the funding estimates for the outbreak response changed from US\$4.8 million in April 2014 to US\$71 million in August of the same year, then to US\$490 million just a few weeks later. In September 2014, WHO estimated that the cost of the response had spiraled up US\$1 billion (Flessa and Marx 2016; Grépin 2015; Harman 2014). By December 2014, the official WHO request for funding to respond to the 2014-15 WA Ebola outbreak had risen to US\$1.5 billion (Global Ebola Response 2014).

Even as the estimated cost surged nearly 10-fold, resource mobilization took off slowly (Lupel and Snyder 2017). As a result, there were significant funding gaps in the immediate response (Elmahdawy and others 2017). As of November 2014, eight months after the declaration of the outbreak, a financing gap of 39 percent, or US\$988 million, remained (Office of the UN Special Envoy on Ebola 2014). The Ebola response was characterized by inadequate coordination of national and international partners, which impacted the timeliness and efficiency of the resource mobilization and interventions (Coltart and others 2017; Cangul and others 2017; Ross and others 2017; Fielding and others 2016; Gostin and Friedman 2015; Moon and others 2017). In contrast, when Ebola was detected in Nigeria, caused by an imported case linked to the West Africa outbreak, the disease was controlled swiftly due to effective, government-led coordination as well as to multisectoral engagement. (Bali and others 2016; Cangul and others 2017).

The creation of UNMEER helped to galvanize political support for the response. However, UNMEER's lack of proximity to the crisis ${ }^{7}$ made field coordination challenging (Lupel and Snyder 2017; USAID, OFDA 2018). The lack of coordination contributed to delayed response efforts and duplication of activities and funding in some areas (Elmahdawy and others 2017).

\footnotetext{
${ }^{6}$ The delay from outbreak occurrence to confirmation in Guinea was approximately four months. The delay between the first confirmed case and the declaration of emergency in Guinea was nearly five months.

7UNMEER headquarters was in Ghana, a nonaffected country.
}

Delays in disbursement of funds and effective use of financing were exacerbated by bureaucracy, earmarked and inflexible funds, and poor transparency and information sharing. These delays in funding led to a realization that flexible (un-earmarked), rapidly disbursable funds are critical to respond to the changing needs of a public health emergency (DuBois and others 2015). Lack of strong governance and accountability as well as systems to track funds also hindered the international response to the Ebola outbreak. Low institutional capacity to manage data collection, keep records, ensure proper procurement, and enforce financial management meant there were instances of corruption, which further reduced trust in government (Coltart and others 2017; Elmahdawy and others 2017). For example, there were reports of officers being bribed at the West Point area of Liberia to break quarantine (Pring 2015); and cases of ghost workers being paid in Sierra Leone, which delayed salaries for front line responders and led to strikes and interruption of activities (Audit Services 2015a, 2015b).

The outbreak underscored the importance of investing in preparedness and disease detection, the importance of community engagement, and the necessity for financing mechanisms that are quick and easy to activate and flexible enough to address changing needs in an unpredictable, dynamic outbreak (World Bank 2017a; Govindaraj, Herbst, and Clark 2017; Oleribe and others 2015). Major global missions that reviewed the West Africa Ebola response outlined several lessons and recommendations for WHO, UN, World Bank, and other development partners. These included to (1) strengthen IHR core capacities, (2) improve community engagement, (3) institute system-wide accountability in response operations, (4) improve donor coordination, and (5) establish contingency financing for emergency response (Gostin, Mundaca-Shah, and Kelley 2016; Gostin and others 2016; Kikwete and others 2016; Moon and others 2015; WHO 2015a).

Financing the WA 2014-15 Ebola response. The final report, "Resources for Results," revealed that, as of October 31, 2015, a total of US\$5.9 billion had been disbursed to respond to the 2014-15 Ebola outbreak (Office of the UN Special Envoy on Ebola 2016). Of the US\$5.04 billion pledged for immediate response, US\$4.67 billion had been disbursed by October 31, 2015 (Office of the UN Special Envoy on Ebola 2016). Bilateral donors collectively disbursed over US\$3.9 billion in 
FIGURE 2 Amount of WA 2014-15 Ebola Financing Disbursed by Donor

\section{WHERE DID THE MONEY COME FROM?}

Amount disbursed by donor category

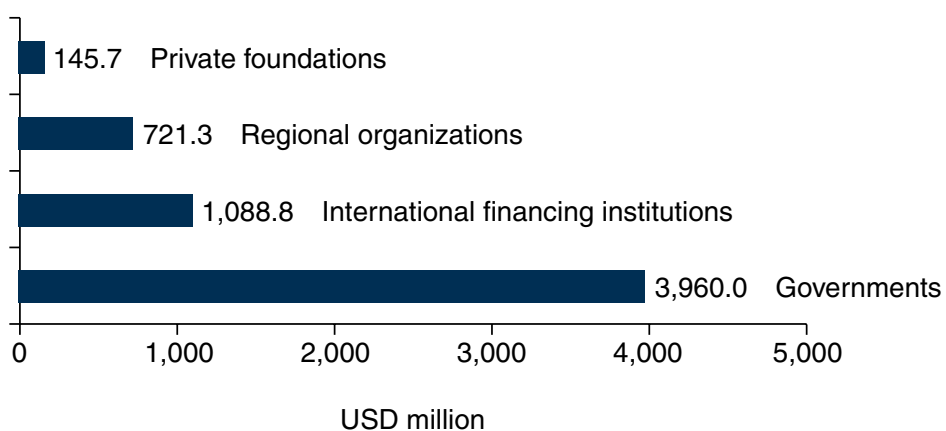

Largest bilateral donors:

(contribution > \$20 million)

- US

- UK

- Japan

- Germany

- China

- France

- Canada

- Netherlands

- Denmark

- Belgium

- Ireland

- Norway

- Switzerland

- Australia

- Russia financing (Figure 2). Financing disbursed to the affected countries (including debt relief and financial assistance from the WBG and the International Monetary Fund (IMF) amounted to US\$1.352 billion, while United Nation entities received US\$1.157 billion (Office of the UN Special Envoy on Ebola 2016). That only 22.9 percent of the financing was disbursed directly to countries reflects the top-down nature of emergency aid and the challenges pertaining to country ownership of the response (DuBois and others 2015).

World Bank response. A number of reports highlight World Bank as one of the first institutions that provided much needed financing to the affected countries (Gostin and others 2016; Frost 2015). The World Bank pledged US\$200 million in financing by August 4, 2014. However, by April 2015, total World Bank and IMF funding for the outbreak and recovery efforts, including debt relief, exceeded US\$1.6 billion (Office of the UN Special Envoy on Ebola 2016). Beginning in August 2014, the World Bank restructured three existing projects. Two of these projects ${ }^{8}$ totaling US\$6 million were restructured by August 8, 2014, and an additional US\$6 million was advanced to Guinea through reallocation of a social protection project.

${ }^{8}$ Sierra Leone Reproductive and Child Health Project (SLRCHP) and Liberia Health Systems Strengthening Project (LHSSP).
In parallel, World Bank staff prepared to activate the IDA Crisis Response Window (CRW) by modifying it to enable funding for public health emergencies (Box 1), and activated for US\$420 million (World Bank 2015a).

Strong support from World Bank senior managers and the ability of task teams to coordinate various moving parts enabled the World Bank to utilize the IDA funds from CRW to launch the Ebola Emergency Response Project (EERP), and disburse US\$105 million in financing within 47 days (World Bank 2014a; Frost 2015)..$^{9}$ Later, financing of US\$285 million was added to bolster support to the EERP response efforts (World Bank 2014b).

Of the US\$1.62 billion financing attributed to the World Bank Group for the outbreak, US\$518 million was provided for immediate response. This amount included US\$390 million financing via EERP and additional financing, US\$18 million in reallocated funds, and US\$110 million in budget support. Post-Ebola recovery efforts were supported by US\$650 million in IDA grants and loan contributions and US\$450 million in International Finance Corporation (IFC) investments in commercial financing (Reynolds 2015). ${ }^{10}$

${ }^{9}$ Time from WBG pledge on August 4, 2014, to EERP effectiveness. EERP was approved by the board on September 16, 2014, and became effective on September 19, 2014.

${ }^{10}$ Including lines of credit to enable trade and employment. 
BOX 1 Avian Influenza: Missed Opportunity for Preparedness

Between 2005-10, the global community committed US\$3.9 billion to Avian and Pandemic Influenza preparedness and response. Of this amount, US $\$ 2.7$ billion was disbursed (WBG 2010). Avian Influenza was recognized as one of the primary zoonotic threats to global health security, and a number of global initiatives to prepare for outbreaks were supported, including the World Bank Pandemics Global Program and Partnership (PGPP), which spanned 2006 to 2020. PGPP was coordinated with key human and animal health organizations including WHO, FAO, OIE, and UNSIC; and focused on advocacy, coordination, strengthening health systems, and complying with IHR. Several initiatives were included in the PGPP including the Global Pandemic and Avian Influenza (GPAl) initiative ${ }^{11}$ (over US\$1 billion), and the Avian and Human Influenza (AHI) Facility trust fund (US\$127 million) for GPAI projects. ${ }^{12}$ The World Bank also managed a multi-donor reporting system between 2005-10, involving financing US $\$ 4$ billion from 35 donors to over 100 lower- and middle-income countries (LMIC).

"The Fifth Global Progress Report on Avian and Pandemic Influenza: A Framework for Sustaining Momentum" was endorsed at the April 2010 International Ministerial Conference on Avian and Pandemic Influenza (IMCAPI) in Hanoi (WBG 2010). Three streams of work were agreed: (i) prevention and control of the highly pathogenic Avian Influenza, (ii) adoption of the animal-human-environmental "One Health" approach, and (iii) readiness for response to influenza pandemics. The consensus reached through the "Hanoi Declaration" stated that international policies and financial support need to transition from emergency projects and special initiatives to build long-term system capacity for multisectoral preparedness and response to pandemics to avert potential pandemics of animal origin, and mainstream investments and capacity in country health systems (Jeggo and Mackenzie 2014; WBG 2010).
The World Bank endorsed the declaration and three priority program areas: ${ }^{13}$

1. Continue collaboration among governments, industry, and communities to pursue prevention, preparedness, and response systems in animal, human, and environmental health disciplines

2. Move from limited emergency measures, to long-term investments in animal and human health to sustained disease prevention and development of capacities to respond and eradicate disease at their sources and before cross-border regional and global spread

3. Emphasize strengthening country/local animal and human systems including emergency response and contingency planning reflecting global IHR and OIE veterinary standards.

Despite these commitments, in the wake of the 2008 financial crisis, funding for disease preparedness lagged, and program priorities shifted. Prior to the West Africa Ebola outbreak in 2014, little progress had been made in adapting financial tools to respond to emerging disease threats. An example was the absence of infectious disease outbreaks from funding eligibility under the Crisis Response Window. In the 2013 Independent Evaluation Group (IEG) report on the GPAl, evaluators noted that the report's ". . . most important finding was that after 2010, the World Bank has not sustained the zoonotic disease risk management and pandemic preparedness agendas and failed to mainstream them into Bank strategy and operations."(IEG 2013). As detailed in this report, momentum has been re-established to support preparedness for outbreaks. However, Avian Influenza should be held up as an example of how not to allow priorities to be diverted from financing longer term preparedness efforts. Otherwise, the global community may find itself once again unable to respond to a global pandemic.
Concurrently, World Bank also launched a US\$53 million Ebola Recovery and Reconstruction Trust Fund (EERTF) (Box 2). This effort was a Multi-Donor Trust Fund (MDTF), which received contributions from Denmark, Japan, the
Netherlands, Norway, Russia, and the United Kingdom. The pooled MDTF mechanism enabled resources to become quickly available and expedited the implementation of 19 Ebola recovery projects (Rey 2018; World Bank 2018).

\footnotetext{
${ }^{11}$ Approved in January 2006, GPAI provided for an "adaptable program lending" (APL) approach that financed 72 projects in 60 countries; with US\$1.3 billion in financing for country-based programs from IBRD/IDA/TFs. GPAl projects ending in FY 2015.

${ }^{12}$ The AHI facility closed in 2014.
}

\footnotetext{
${ }^{13}$ Animal and Pandemic Influenza: A Framework for Sustaining Momentum. Fifth Global Progress Report.
} 
BOX 2 World Bank Ebola Recovery and Reconstruction Trust Fund (ERRTF)

The World Bank Ebola Recovery and Reconstruction Trust Fund (ERRTF) was launched in September 2014 to support the post-Ebola economic, health, and social recovery of Guinea, Liberia, and Sierra Leone. These funds provided support to recovery and reconstruction efforts and to bridge financing gaps between emergency response and long-term development investments such as the REDISSE program.
The fund contributed US\$51 million to economic, social, and health systems recovery, including supporting critical activities around infrastructure, supplies and equipment, medicines, capacity building, education, and livelihoods (Table 1). The remaining US\$1.55 million is supporting the ongoing 10th Ebola outbreak in DRC.

TABLE 1 ERRTF Contributing Partners

\begin{tabular}{|l|c|}
\hline PARTNERS & $\begin{array}{l}\text { AMOUNT CONTRIBUTED } \\
\text { (US\$ MILLION) }\end{array}$ \\
\hline Norway Ministry of Foreign Affairs & 10.2 \\
\hline Danish Ministry of Foreign Affairs & 4.9 \\
\hline Japan Ministry of Foreign Affairs & 20.0 \\
\hline Russian Federation Ministry of Finance & 3.0 \\
\hline United Kingdom (DFID) & 4.5 \\
\hline Norwegian Agency for Development Cooperation (NORAD) & 4.9 \\
\hline Netherlands Ministry of Foreign Affairs & 5.4 \\
\hline
\end{tabular}

Other international financing. Bilateral donors were by far the biggest contributors to the 2014-15 Ebola response (Figure 2). By December 2014, the U.S. government had allocated US\$2.4 billion for international efforts (USAID 2016). Financing support came from multiple African institutions. The African Development Bank (AfDB) contributed US\$525 million in grants and loans. The African Union made direct contributions of US\$1 million from the AU Special Emergency Assistance Fund for Drought and Famines, with another US\$1 million contributed from Special Fund Contributions for IDPs and Refugees (Loewenson, Papamichail, and Ayagah 2015). African resources in total contributed US\$600 million to the outbreak (Loewenson, Papamichail, and Ayagah 2015).

The United Nations leveraged pooled funding from 43 UN Member States in the form of the Ebola Response Multi-Partner Trust Fund (MPTF), which provided a flexible funding pool for UNMEER and other UN partners to respond to the epidemic. The Ebola MPTF leveraged US\$157 million to finance over 70 different projects (UNMPTF 2017). One of the major lessons documented from the World Bank MDTF and the UNMPTF is that pooled funds can fill critical gaps in financing during a health emergency through rapid injection of non-earmarked funds (Lupel and Snyder 2017).

\section{GENERAL LESSONS LEARNED}

Multiple studies have looked at the overarching lessons from the 2014-15 West Africa Ebola epidemic (Coltart and others 2017; Commons 2016; Gostin and Friedman 2015; Heymann and others 2015; Moon and others 2017; Moon and others 2015; Ravi, Snyder, and Rivers 2019; UNMPTF 2017; USAID, OFDA 2018; WHO 2015a; Yamey and others 2017). The following major themes stand out:

1. As the first line of defense, it is important to strengthen public health capacity and preparedness in the region, including human and animal disease surveillance. Swift detection enables swift response and more lead time to mobilize resources. 
2. Timely and agile financing for rapid response is critical, but sustainable financing for routine preparedness and response systems in the region is equally important. The outbreak underscored the importance of investing in disease detection, the importance of community engagement, and the need for financing mechanisms that are quick and easy to activate and flexible enough to adapt to rapidly shifting needs in an unpredictable, dynamic outbreak.

3. Effective preparedness and response depend on having in place an adequately financed and countryowned public health system.

\section{KEY STUDY FINDINGS}

Governance. Weaknesses in country ownership, leadership, operational management, and the capacity to coordinate multiple implementing partners were evident from the outset. Additional related problems arose from the lack of transparent decision making, competing lines of action, duplication of efforts, and lack of community trust.

Efficient financing. The mobilization of domestic and external financial resources initially was delayed primarily due to the late detection, confirmation, and declaration of the emergency. Once the funds were committed, cumbersome country and external donor procedures and time-intensive procurement systems further delayed effective containment operations.

The World Bank's grant-funding mechanisms were inadequate and overly complex for use in a public health emergency. Immediate steps had to be taken to modify instruments, such as the World Bank's Crisis Response Window, to make them responsive to health emergencies. Given the instruments available, the accelerated WBG effort successfully overcame many constraints in team organization, coordination among multiple partners, and expedited project approval and disbursement. Nevertheless, the Bank's efforts also underlined the necessity to develop and adapt financing mechanisms for public health emergencies.

The international response eventually gained momentum through contributions of the WBG, United States, United Kingdom, United Nations, and many other donors. Nevertheless, by the time funding became available, geographic transmission was widespread, and much of the damage already had been done. More modest and flexible funding, if made available earlier, may have more effectively contained the epidemic, limiting human and economic losses, and obviated the need for the unprecedented amount of resources required to end the outbreak.

Effective use of resources. Weak and often opaque country financial management systems as well as outdated information systems made financial accountability a persistent problem. Lack of financial accountability had implications for the efficient use of resources and wasteful spending. Inefficient administration of health worker hazard incentives was a critical problem and severely impeded the response workforce. Lack of in-country capacity to manage local procurement also contributed to excessive response costs and often resulted in the payment of high overhead costs to external implementing agencies.

Preparedness. The weaknesses in the countries' outbreak readiness were starkly revealed during this epidemic. Disease surveillance, particularly at the human/animal/environmental interface, was sorely lacking in all three countries. Also lacking were laboratory diagnostic capacity, human resources with skills in applied epidemiology, community intervention, and emergency management. The epidemic underscored the urgency of investing to strengthen health systems and human resource development for outbreak prevention, detection, and response. Another gap to be filled is the development of a multisectoral One Health Approach to public health risk management that coordinates across the human, animal, and environmental sectors.

\section{LASSA FEVER EPIDEMIC, NIGERIA, 2018}

Efficient coordination improved timeliness of resource mobilization, but delays in financial request and centralized procedures delayed disbursements

\section{BACKGROUND}

Lassa Fever is endemic to Nigeria. Typically, over 100 infections occur every year, usually in specific geographic areas of the country. The illness is a viral hemorrhagic and zoonotic 
disease, transmitted to humans on food or household goods contaminated with rat urine or feces.

2018 outbreak timeline. A cluster of four cases of Lassa Fever among health care workers in Ebonyi State were reported to the Nigeria Centre for Disease Control (NCDC) in January 2018. The government immediately deployed an outbreak investigation team (NCDC 2018c). These cases, which involved health care workers, were the harbinger of what was to become, at that time, the largest Lassa Fever outbreak in the country's history. In January 2018 alone, there were 203 suspected cases-more in one month than the 143 confirmed cases in all of 2017, or the 109 cases in all of 2016 (Beaubien 2018). WHO graded the outbreak as Level 2 on February 6, 2018 (WHO AFRO 2018). The outbreak was upgraded by the government to a Level 3 on February 28, 2018. The outbreak was declared over on May 10, 2018, by which time it had lasted 4.5 months and resulted in 1,706 suspected cases, 423 confirmed cases, and 106 confirmed deaths (NCDC 2018a).

Response. Since Lassa Fever is endemic in Nigeria and the country faces yearly outbreaks, the initial cases were not interpreted as indicating an unusual or severe event. However, the cluster of cases among health care workers in January 2018 and the rapid increase in case reporting that month indicated that the outbreak had deviated from patterns of previous outbreaks. Transmission took place in a densely populated area in which surveillance was compromised by limited health care worker presence. The challenge of response was compounded by a labor union strike, ${ }^{14}$ hostile community reactions in some regions, and lack of preparedness at state and local levels. The endemic nature of Lassa Fever resulted in complacency and delayed comprehension of the magnitude of the outbreak. The severity of the outbreak quickly outstripped resources, making for cumbersome, inefficient operational coordination, particularly at the state and local levels. Although NCDC was instrumental in the response efforts, ${ }^{15}$

\footnotetext{
${ }^{14}$ Focus group with state epidemiologists and Emergency Operations Center (EOC) leads highlighted that health care worker ( $\mathrm{HCW}$ ) strikes interrupted service delivery for Lassa Fever due to the high risk of Lassa Fever for HCWs, and issues of delayed/low hazard allowances.

${ }^{15} \mathrm{NCDC}$ started to respond from January 2018 and played a key role in coordinating and implementing Nigeria's national response to Lassa Fever.
}

bureaucratic procedures and lack of legal autonomy delayed Nigeria's request for external assistance. ${ }^{16}$

\section{FINANCING THE OUTBREAK RESPONSE}

Prior to 2018, Nigeria had no contingency preparedness plan in place for a Lassa Fever outbreak. On March 2, 2018, 24 days after the initial emergency had been declared, ${ }^{17}$ a SRP was formulated with WHO's assistance. The SRP estimated a funding gap of US\$4.85 million. WHO promptly released US\$950,000 from its CFE to cover needs for the initial three months (WHO 2018a)..$^{18}$

World Bank activates CERC. Of the estimated US\$4.85 million required to implement the SRP for Lassa Fever, the Government of Nigeria identified a US\$2.5 million funding gap (World Bank communications). On March 12, 2018, NCDC requested the Ministry of Health ( $\mathrm{MOH})$ and the Ministry of Finance (MOF) to seek financing from the World Bank REDISSE Program under its CERC. The request was made on March 29, 2018 - within weeks of the declaration of effectiveness for the REDISSE 2 Project in Nigeria. ${ }^{19}$ The Bank activated the CERC within nine days, on April 6, 2018. The Government of Nigeria directed that the funding be provided to $\mathrm{WHO}$ and the United Nations Children's Fund (UNICEF) to complement the ongoing response in the country. The Bank disbursed a total of US\$2.5 million as follows: US\$565,000 to UNICEF on April 2 and USS\$1,935,00 to WHO on June 27, 2018. This was the first time that the World Bank had activated a CERC mechanism to address a public health emergency in Africa.

Use of CFE and CERC mechanisms for financing, and the establishment of the Lassa Fever Technical Working Group (TWG) by NCDC were some of the game changers that facilitated

\footnotetext{
${ }^{16}$ Review of documents and findings from this study reveal that the time between NCDC's request to $\mathrm{MOH}$ and MOF for WBG financing and the receipt of Nigeria's CERC activation request by the World Bank was 18 days.

${ }^{17}$ Nigeria declared Lassa Fever as a Level 2 emergency on January 22, 2018 and a Level 3 emergency on February 28, 2018.

${ }^{18} \mathrm{CFE}$ disbursements are aligned with WHO's Emergency Response Framework (ERF): "The Emergency Framework, which provides all hazards of emergency assistance, is being piloted according to a country model based on a defined, graded level of emergency. Level 1 is expected to be managed at the country level; Level 2 requires regional support; and Level 3 depends on global WHO headquarters engagement for up to US\$1 million in eligible assistance."

${ }^{19}$ REDISSE had been declared effective in Nigeria one month earlier on February 13, 2018.
} 
responses to the Lassa Fever outbreak. Lack of familiarity with the CERC financing instrument ("learning by doing"); and delayed contract signing (among Nigeria, WHO, and UNICEF) due to centralized and bureaucratic procedures were some of the challenges reported during the interviews. The contract between the Government of Nigeria and UNICEF was signed on April 18, 2018. The contract between the Government of Nigeria and WHO was signed on June 11-well after the outbreak had been declared ended on May 10, 2018 (NCDC 2018b, NCDC 2018d). The findings are elaborated in the next section.

\section{STUDY FINDINGS}

Governance. In the last two years, NCDC has strengthened its leadership capacity, activated five emergency operations (including for meningitis, cholera, and monkey pox), and deployed 32 outbreak investigation teams. However, during the 2018 Lassa Fever outbreak, the legal status of NCDC was still under discussion and the organization was dependent on the mediating authority of the $\mathrm{MOH}$ to request the MOF for funding, contributing to the delayed response. The Nigeria Health Act provides for an earmarked contingency fund for health emergencies, although it is limited. The Nigerian Parliament is supportive of health security and a stronger NCDC. As of November 11, 2018, the Centre has had full legal status to prevent, detect, and respond to public health threats. It no longer requires the mediation of $\mathrm{MOH}$ to engage with $\mathrm{MOF}$ to request external financial assistance. These changes endow NCDC with greater responsibility for and authority to respond to outbreaks and other public health threats.

Efficient financing. Findings from this study reveal that sufficient resources were mobilized, ${ }^{20}$ but the request for CERC activation by the Federal Government of Nigeria (FGON), and the subsequent disbursement of CERC funds was delayed for procedural, interministerial reasons (Figure 3). Although CFE and CERC were touted as game changers in agile financing, respondents highlighted the impact of centralized processes and lack of familiarity with new instruments for contract signing and disbursements. Instances were reported when the

\footnotetext{
${ }^{20}$ CERC was activated to cover the financing gap from Lassa Fever SRP.
}

perceived need for adjustments in the use of CERC resources ${ }^{21}$ required additional documentation. Delays in contract signing made it difficult for agencies to utilize resources most efficiently to meet the outbreak at its peak. The CERC should be sufficiently flexible and nimble to respond efficiently to the changing dynamics of epidemiologic emergencies as they run their course. After Action Review (AAR) of CERC after 12 months to identify bottlenecks, and workshops to familiarize country managers, and countries with CERC and other such financing mechanisms/tools would improve efficiency of financing.

Effective use of resources. National governments and international partners' lack of familiarity with in-process amendments under the new World Bank financing procedures delayed the use of funds. FGON's centralized procurement policies and procedures and the lack of prepositioned agreements delayed procurement contracting. Although resources at the national level were sufficient, state and local levels experienced a significant lack of funding. All external financing was required to be deposited in a single Treasury account, making the approval processing cumbersome. Engagement with the private sector would maximize resources for outbreak response and could be leveraged to reduce misuse of funds. ${ }^{22}$

Preparedness. Due to its "intangible nature," states frequently invest very little in preparedness. The REDISSE project, with its surveillance dimension, integrates the preparedness function in a financing tool. This innovative combination makes for easier, more prompt procurement. Going forward, an analysis of the long-term socioeconomic impacts of Lassa Fever would help guide policy on domestic public financing and contingency budgeting and program design, as well as rationalize and improve the cost-effectiveness of prevention and preparedness.

\footnotetext{
${ }^{21}$ Accidental omission of certain reagents from the submitted emergency plan.

${ }^{22} \mathrm{An}$ example is the use of vouchers for fuel (in collaboration with major oil and gas companies) instead of financing of fuel.
} 
FIGURE 3 Nigeria Lassa Outbreak, 2018: Epidemiological Curve, Key Events, and Funding Commitments

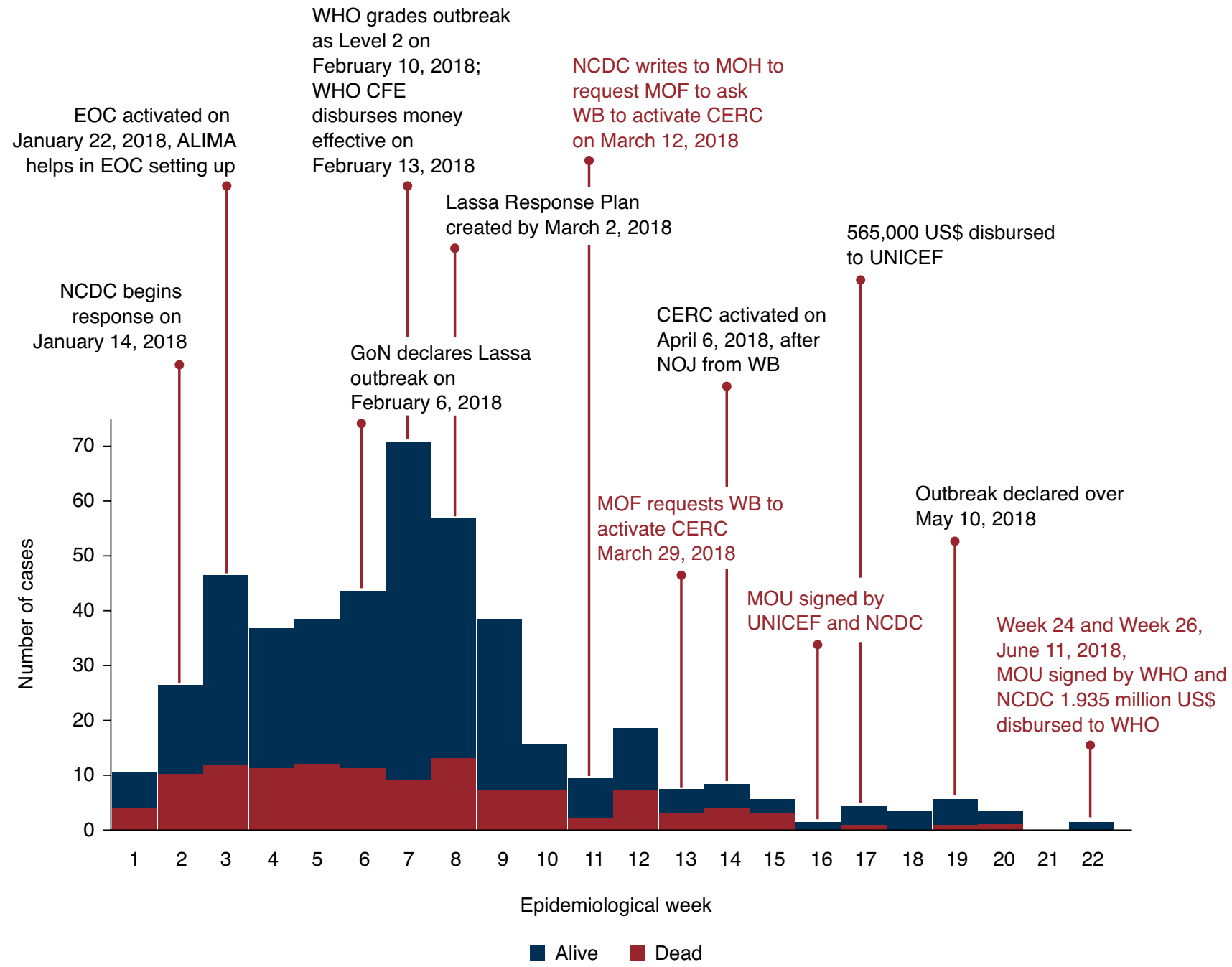

BOX 3 Regional Disease Surveillance Systems Enhancement (REDISSE) Program

REDISSE is an interdependent series of projects to strengthen national and regional capacity for disease surveillance and response in West Africa. This program is at the heart of the World Bank's post-emergency response to the 2014-15 Ebola outbreak. The REDISSE Program has two objectives: (1) to address systemic weaknesses within the animal and human health systems that hinder effective cross-sectoral and cross-border collaboration for disease surveillance and response; and (2) in the event of an eligible emergency, to provide immediate and effective response to said eligible emergency. The REDISSE Program has five components: (1) surveillance and information systems; (2) strengthened laboratory capacity; (3) epidemic preparedness and rapid response (including a CERC or "zero-dollar component" for emergencies); (4) workforce training, deployment, and retention; and (5) institutional capacity building for project management, coordination, and advocacy.

The REDISSE Program currently supports 11 countries in West Africa as well as the West African Health Organization (WAHO), including Guinea, Senegal, Sierra Leone, WAHO (REDISSE Phase 1); Togo, Guinea-Bissau, Liberia, Nigeria (REDISSE Phase 2); and Benin, Niger, Mauritania, Mali (REDISSE Phase 3). Present financing for the REDISSE Program is US $\$ 390.8$ million. REDISSE Phase 4 is under preparation and will expand the program to five countries in neighboring Central Africa (Angola, Central African Republic, Chad, Congo, and Democratic Republic of Congo (DRC). 
FIGURE 4 DRC 9th Ebola Outbreak: Epidemiological Curve, Key Events, and Funding Commitments, 2018

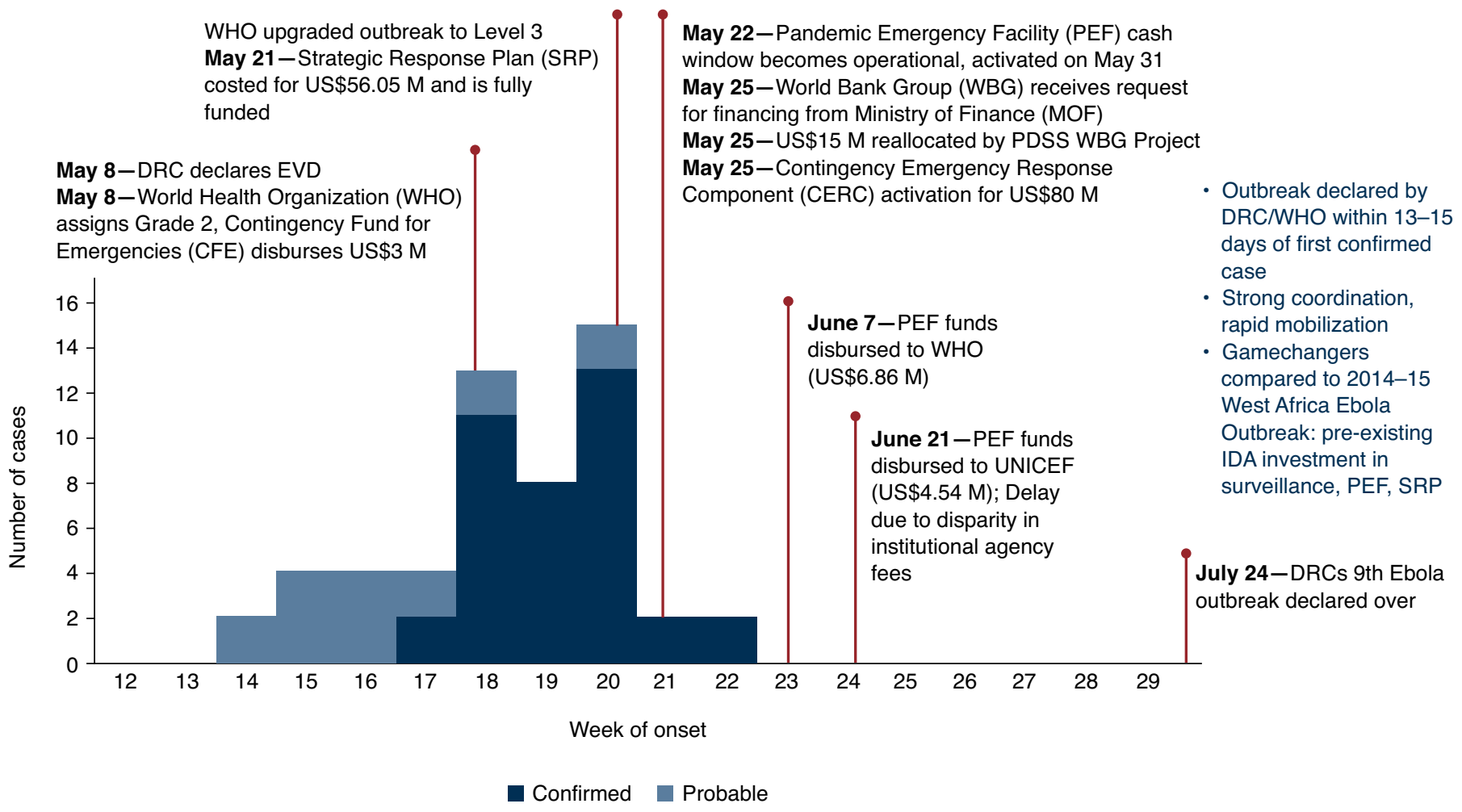

\section{Ebola, OUtBreaks \#9 ANd \#10, Democratic REPUBLIC OF CONGO (DRC), 2018-19}

Strong coordination, rapid resource mobilization, but some delays in disbursements

\section{BACKGROUND}

Ninth Ebola outbreak in DRC. The first confirmed cases of Ebola in DRC were recorded on April 23-25, 2018, followed by a cluster of 21 cases reported on May 3, 2018, by the Equateur Provincial Health Division. $\mathrm{MOH}, \mathrm{WHO}$, and Médecins Sans Frontières (MSF) carried out a joint field investigation on May 5, 2018. Following positive test results at the national laboratory in Kinshasa, on May 8, 2018, MOH officially declared the 9th outbreak of Ebola in DRC since the disease had been identified in the country 40 years ago. The 9th Ebola outbreak, graded as a WHO Level 3 outbreak (that is, requiring WHO HQ intervention), was declared ended on July 24, 2018. In total, there were 54 cases resulting in 33 deaths, and it took 77 days to contain the outbreak (WHO 2018b). The epidemiologic curve of the 9th Ebola outbreak is shown in Figure 4.
Tenth Ebola outbreak in DRC. The 10th Ebola outbreak in the North Kivu and Ituri provinces of DRC was declared by the Ministry of Health on August 1, 2018 (WHO 2019a) and was determined to be distinct in origin from the 9th outbreak. Ebola transmission was ongoing at the time that this report was published. In contrast to the 9th outbreak in Equateur, this outbreak occurred in an area of ongoing insecurity and humanitarian crises. Being in this environment led to delays in outbreak detection, declaration, and response (Munster and others 2018).

While community deaths started occurring in April 2018, the alerts were received only in late July due to difficulty in accessing the region and frequent health care worker strikes for nonpayment of salaries (Gostin, Kavanagh, and Cameron 2019; Fanning 2018). The 10th Ebola outbreak is the second largest Ebola outbreak to date with 1,400 confirmed and 66 probable cases, including 92 health workers; and over 957 deaths as of May 1, 2019. After the outbreak was confirmed in eastern DRC, on August 8, 2018, officials began Ebola vaccination of at-risk populations. As of May 1, 2019, over 106,872 people have been vaccinated (WHO Situation Report 39, 2019). 


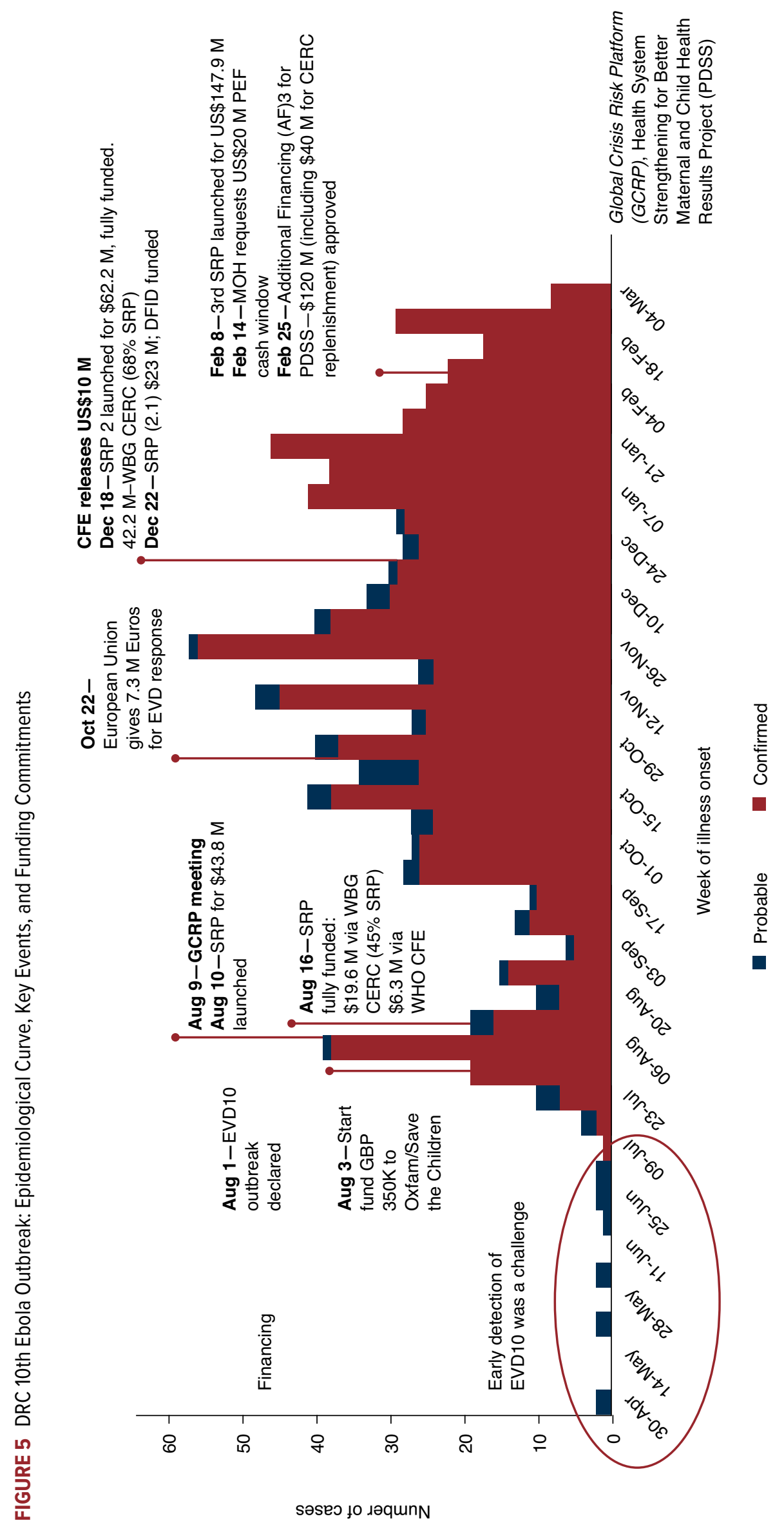


The outbreak has not yet spilled across international borders. Nevertheless, extensive Ebola preparedness effortsplanning, identifying, and prepositioning financial and technical resources, and vaccinating health care workersare being conducted in the countries bordering the affected areas, in particular Rwanda, South Sudan, and Uganda.

Despite the availability of financing and extensive national and international efforts to curb transmission, the response has been hampered by insecurity, weak community engagement, limited coordination with the humanitarian sector, and poor infection prevention and control (IPC) implementation leading to health care worker infections. Since August 2018, over 237 security incidents ${ }^{23}$ (as of December 22, 2018)-including several attacks on first responders-have impacted the response (DRC Ministry of Health 2018b). Community mistrust and poor access to rebel-held regions have made contact tracing and vaccination extremely difficult. The impact of financing and responding to outbreaks in insecure areas is further explored in Box 3. The epidemiologic curve of the 10th Ebola outbreak is shown in Figure 5. Because the outbreak was ongoing at the time of this study, the data cut-off was selected at the time that the third SRP was launched, with subsequent World Bank additional financing made available to support the efforts.

\section{FINANCING THE OUTBREAK}

WHO disbursed the first US\$1 million (of US\$3 million total to DRC for the 9th Ebola outbreak) from CFE on May 8, 2018the same day that the 9th Ebola outbreak was declared. ${ }^{24}$ Also on May 8, 2018, the World Bank authorized the use of US\$15 million from the existing Health System Strengthening for Better Maternal and Child Health Results Project (PDSS), which included a component on disease surveillance. Domestic emergency government funding included US\$500,000 from the DRC $\mathrm{MOH}$, and an additional US\$4 million in special emergency funds were disbursed by the DRC Treasury. ${ }^{25}$ On May 21, 2018, MOH, WHO, and partners finalized a jointly

\footnotetext{
${ }^{23}$ As per the Human Rights Watch data on https://kivusecurity.org, there have been 823 security incidents in the Kivu region between August 31, 2018, and April 30, 2019.

${ }^{24}$ Another US\$1.5 million from WHO CFE was disbursed for preparedness in neighboring countries.

${ }^{25}$ Based on verbal report.
}

prepared three-month Strategic Response Plan and costed it at US\$56 million.

\section{Activation of World Bank emergency financing mecha-} nisms. On May 22, 2018, the World Bank activated for the first time the cash window of the PEF. ${ }^{26}$ The payout of US\$11.4 million occurred on June 1, 2018, and was financed by the German government. At MOH's request, the funds were disbursed to WHO (\$6.86 million) on June 17, 2018, and to UNICEF (\$4.54 million) on June 18. These disbursements were made considerably more quickly than the disbursements made to WHO and UNICEF during the Lassa Fever outbreak in Nigeria. Notably, the Bank requested to activate the PEF cash window during the World Health Assembly (WHA), which had drawn many of the key PEF stakeholders on-site, thus facilitating communication and coordination.

On May 25, 2018, the World Bank activated a CERC mechanism, making an additional US\$80 million available for emergency use. Although these funds were not engaged ${ }^{27}$ for the 9th Ebola outbreak response, they were effectively prepositioned to contribute to the 10th outbreak response in North Kivu and are being used during this outbreak. According to the UNOCHA tracking system, for the 9th Ebola outbreak, a total of US\$63 million was committed to the DRC from various external sources. Of this total, the World Bank provided US\$26.4 million, and US\$36 million of the external contributions was channeled via WHO. Unspent funds were allocated to the 10th Ebola outbreak. ${ }^{28}$

For the 10th outbreak, both the 1st SRP (US\$43.8 million) and 2nd SRP (\$61.2 million) appeals were fully funded. The World Bank funded 45 percent of the 1st SRP (\$19.6 million, of which US\$10.5 million went to the UN agencies), ${ }^{29}$ and 68 percent of the 2nd SRP (\$42.8 million, of which US\$30 million went to the UN agencies). ${ }^{30}$ Other donors also leveraged pooled funds to finance the response, including EU's Emergency Aid Reserve, WHO's Contingency Fund for Emergencies

\footnotetext{
${ }^{26}$ On May 22, 2018, Germany, as the first bilateral donor, contributed Euro 10 million to the PEF cash window. Germany has since become the largest contributor to the PEF Cash Window, having contributed US\$57 million. ${ }^{27}$ In the absence of the 10th Ebola outbreak, any non-engaged funds or remaining balance from CERC activation would have been returned to the donor project and respective components.

${ }^{28}$ For the 10th Ebola outbreak, World Bank CERC funding ( $\$ 80$ million) was activated to cover a US\$20 million funding gap.

${ }^{29}$ US\$6.5 million to WHO; US\$3.7 million to UNICEF.

30US\$17.2 million to WHO; US\$12.8 million to UNICEF.
} 
(CFE), and UN Central Emergency Response Fund (CERF). Insecurity, lack of infection prevention and control measures, and weak community engagement have prolonged the 10th outbreak, leading to an exponential increase in cost. The 3rd SRP estimated a cost of US\$147.9 million to address the continuing outbreak (DRC Ministry of Health 2018a). US\$20 million of CERC money is available for the 3rd SRP, and the World Bank prepared additional financing of US\$120 million in IDA grants to replenish PDSS project activities and add US\$40 million to the CERC. The Government of DRC also has requested that US\$20 million be mobilized for the PEF Cash Window to contribute to the 3rd SRP funding gaps.

\section{STUDY FINDINGS}

Governance. The leadership and country ownership evident in the DRC government-coordinated 9th Ebola outbreak stands in contrast to those in the West Africa Ebola crisis. The DRC outbreak alert was investigated; confirmatory laboratory tests completed; and outbreak declared all within five days.

Although the response to the 10th outbreak was delayed, the country evidenced strong country ownership, and the SRP tool was used to coordinate and align donors under a single plan. However, the absence of high-level decision makers, ${ }^{31}$ and key implementation partners (including international nongovernmental organization [INGOs] and NGOs) missing from the strategic planning process has been viewed as impeding effective leadership of the response. Community distrust of the central government, compounded by national elections, also has resulted in résistance to, and often violence against, outbreak workers in the communities and hampered response efforts.

Efficient financing. The mobilization of domestic response funding of an initial US\$4.5 million for the 9th outbreak, was relatively prompt and coordinated. The financial response of the international community, starting with the swift disbursement of US\$950,000 from WHO'S CFE, was immediate. World Bank funding (US\$15 million via the PDSS project) also was committed promptly with a June 1, 2018, payout from the PEF cash window of US\$11.4 million. The PDSS project provided an immediate, agile financial response using previously allocated health funding. CERC was activated in response to the 9th outbreak (but later redirected to respond to the 10th Ebola outbreak in DRC).

With the confirmation of the 10th Ebola outbreak, unspent funding from financing the 9th Ebola outbreak was redirected. Donors responded swiftly to the outbreak, and the availability of more agile financing tools enabled prompt prepositioning and repurposing of funds. In particular, the inclusion of CERC in the PDSS project enabled WBG to leverage an uncommitted US\$80 million from the project for the Ebola 10 response. Unspent funds from the ERRTF grant also were repositioned to support these efforts.

Effective use of resources. Lack of pre-negotiated agreements with implementing partners contributed to delays in funding. International implementing agencies often carry significantly higher costs for contracting and organizational overheads. These overheads suggest potential cost savings from increased domestic implementation capacity and local procurement. However, these would need to be balanced against domestic absorptive and implementation capacity.

Preparedness. DRC has experienced periodic Ebola outbreaks and already has established and tested its detection capacity, which was tapped in the 9th Ebola outbreak. In the ongoing 10th outbreak, $\mathrm{MOH}$ has been able to deploy many highly experienced domestic experts in every technical area to work with external partiers in Kivu. Operational readiness is being strengthened in other provinces and in areas at risk of border transmission.

${ }^{31}$ Stakeholders and implementing agencies, including humanitarian partners. 
BOX 4 Impact of Insecurity on Outbreak Detection, Response, and Financing

Over 1.8 billion, or 24 percent, of the world's population are living in fragile and conflict-affected situations (FCAS). This figure is projected to grow to 2.3 billion by 2030 , when an estimated 80 percent of the world's extreme poor will be living in a FCAS (Ovadiya and others 2015; World Bank 2011; OECD 2018). There is a significant overlap between FCAS and global hotspots for infectious diseases, especially in Sub-Saharan Africa (Wise and Barry 2017; Moore and others 2016). ${ }^{32}$ These countries typically spend less on health as a percentage of their GDP. ${ }^{33}$ As a result, they have weaker health systems and are less able to prevent, detect, and respond to outbreaks (Graves, Haakenstad, and Dieleman 2015). FCAS also have limited ability to mobilize domestic resources for health due to the limited presence of the private sector; insecurity-driven conflict; and weak governance (OECD 2018; Witter 2012).

Insecurity compounds the threat of outbreaks in extremely fragile and conflict-affected situations and complex emergencies. ${ }^{34}$ Globally, conflict situations have tripled since 2010, and more countries experienced violent conflict in 2016 than in the last 30 years (World Bank 2017b; OECD 2018). Outbreaks in insecure and conflict-affected environments are becoming the new normal. However, humanitarian aid, technical assistance, access to services, and community engagement frequently are hindered in responding effectively to health emergencies (Culver, Rochat, and Cookson 2017; Spiegel and others 2007). Additional challenges associated with conflict such as forced mass displacement, food insecurity, interruption of essential services, and shortage of vaccines and drugs further elevate the risk of both escalation of outbreaks and spillover events (via interaction with wildlife) (World Bank 2017b; Wise and Barry 2017).

In Syria, the interruption of routine immunization due to the destruction of health care infrastructure, shortage of vaccines, lack of functional roads, and breakdown in the cold chain resulted in the re-emergence of polio in the country (WHO 2014; Culver, Rochat, and Cookson 2017). In the late 1990s, war in Congo exacerbated an ongoing measles outbreak resulting in 3.3 million people being infected (Burki 2013). In Yemen, lack of access to safe water and health care facilities for 16 million people due to relentless conflict led to the largest recorded cholera outbreak in the country, which affected over 1.2 million people (Federspiel and Ali 2018).

The 10th Ebola outbreak was severely exacerbated and lengthened in DRC. Following every episode of violence, the number of newly detected Ebola cases spiked (Figure 6). This spike in new cases likely was due to the lag time in detecting and confirming new cases, which drives increased disease transmission. These scenarios have the potential to be replicated in other countries. The international community needs to be prepared to support outbreak response in uncertain environments.

Not every scenario can be anticipated prior to a disease outbreak. Nevertheless, operational and financing systems can be developed to limit lag times in securing resources to respond to public health emergencies in insecure environments.

- Putting the "agile in fragile" to finance rapid response in extreme FCAS though risk-layering is essential for a timely response to public health emergencies. As detailed in this report, the World Bank and other development partners have optimized their range of crisis response financing instruments to become more agile and responsive to health emergencies (Table 2). The risk-layering of multiple funds and instruments enables meeting epidemic financing needs of different scale, frequency, and severity in extreme conflict situations (Cummins and Mahul 2008; WBG 2018).

- Multi-Donor Trust Funds (MDTFs) and Country-Based Pooled Funds (CBPF) can provide an umbrella for diverse donor participation for a "neutral" and efficient response in extreme FCAS. Although not yet used for pandemic financing, solidarity levies (such as air ticket levies for UNITAID), and social impact bonds that pay for success (such as Humanitarian Impact Bonds) also have potential to enhance agility for pandemic financing.

- Prepositioned agreements, contracts, and agile processes specifically designed for FCAS can improve timely response.

- Private sector actors can be leveraged to respond to crises. Firms often have technical expertise, crisis

(continues)

\footnotetext{
${ }^{32} \mathrm{~A}$ majority of the FCAS are in Sub-Saharan Africa, and 22 of the 25 most outbreak-vulnerable countries are in the same region (OECD 2018; Moore and others 2016).

${ }^{33}$ FCAS spend an average of 6.98 percent of GDP on health, in comparison to the global average of 9.94 percent.

${ }^{34} \mathrm{~A}$ "complex emergency" is defined as ". . a humanitarian crisis in a country, region, or society where there is a total or considerable breakdown of authority resulting from civil conflict and/or foreign aggression."
} 


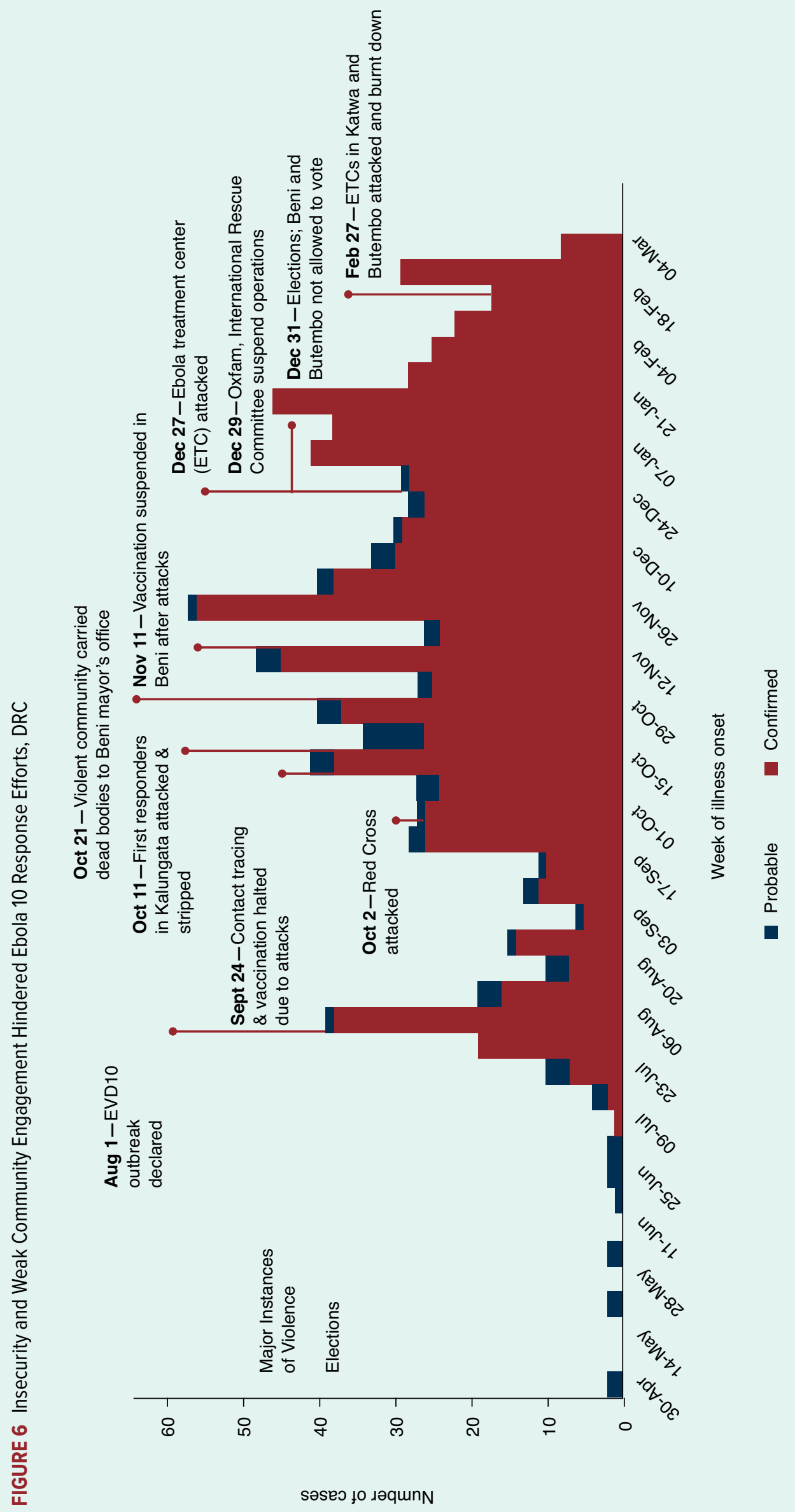


response tools, and logistics networks that can be leveraged to improve access to vulnerable populations. Local businesses can act as intermediaries with NGOs and humanitarian partners to improve access and logistics. The Maximizing Finance for Development (MFD) approach adopted by WBG in 2017 pursues private sector solutions to improve the efficiency of development aid. MFD also holds the potential to leverage the private sector for emergency response. Insecurity and access to finance are the top constraints to private sector operations in crises. Contingent contracting arrangements and MIGA guarantees can help incentivize and mobilize the private sector to respond to an epidemic in crisis.

- Improving governance and coordination for rapid response financing is critical to ensure swift decision making and the ability to coalesce partners during outbreaks. Established in September 2016, the Global Crisis Risk Platform (GCRP) ${ }^{35}$ has enabled WBG to leverage the entire suite of agile financing instruments to support countries to manage crises, including epidemics in extreme FCAS. GCRP played a critical role in facilitating WBG's response to both the famine and cholera emergency in Yemen, as well as the 9th and 10th Ebola outbreaks in DRC (WBG 2018).

TABLE 2 Selected World Bank and Other Development Public Health Emergency Financing Tools and Contingency Instruments

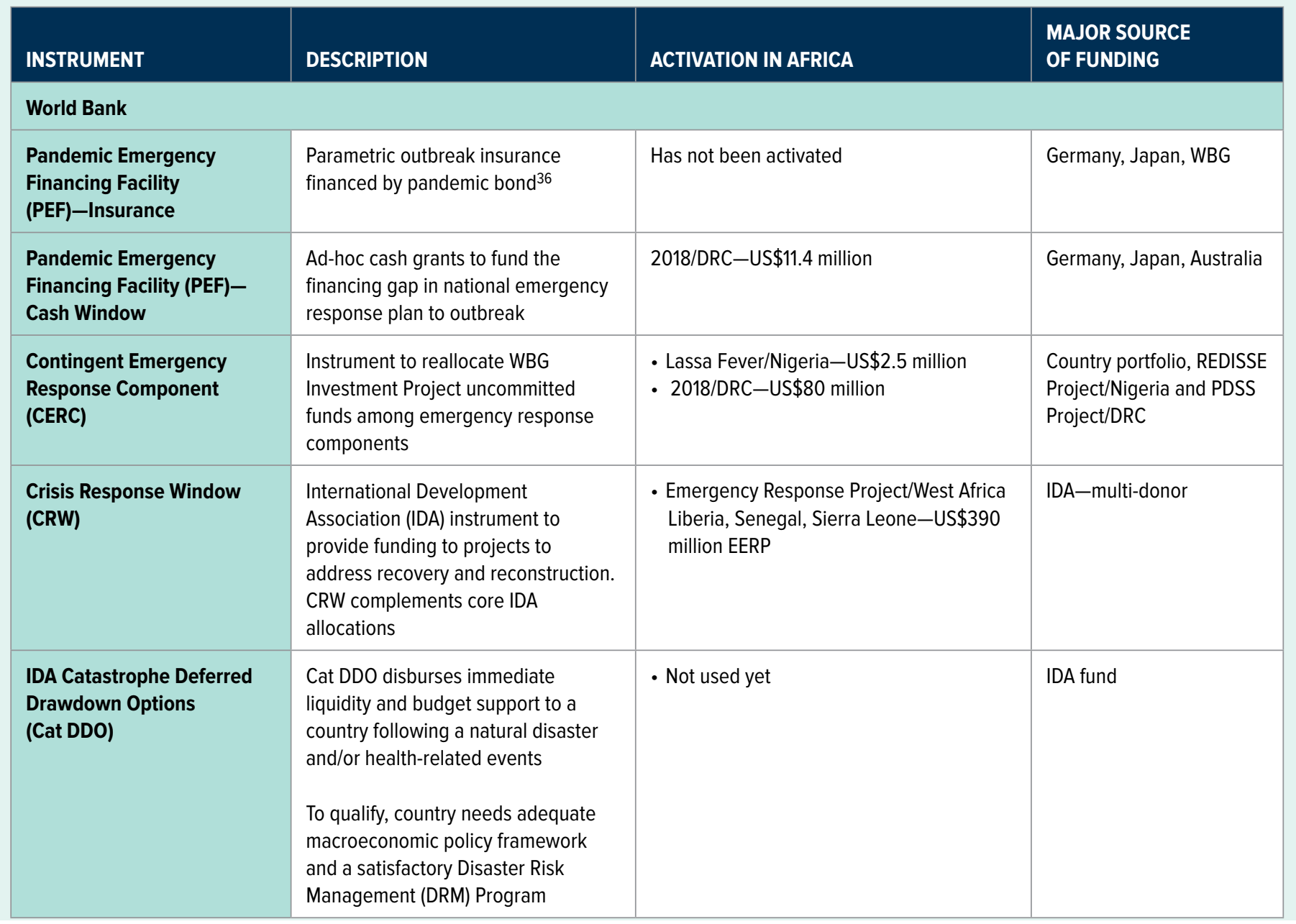

(continues)

\footnotetext{
${ }^{35} \mathrm{GCRP}$ is a network of WBG units that leverages the Bank Group's expertise, products, and services; and pioneers innovative financing solutions to provide crisis risk management support to countries.

${ }^{36}$ Parametric triggers for certain high-impact diseases. Criteria used in PEF parametric triggers include outbreak size (number of cases or deaths), outbreak growth, and outbreak spread. Defined set of viruses covered by the insurance window: New Orthomyxoviruses (does not cover seasonal flu), Coronavirus (SARS, MERS), Filoviridae (Ebola Marburg), and other viral hemorrhagic fevers (CCHF, RVF, Lassa Fever).
} 
BOX 4, TABLE 2 Continued

\begin{tabular}{|c|c|c|c|}
\hline INSTRUMENT & DESCRIPTION & ACTIVATION IN AFRICA & $\begin{array}{l}\text { MAJOR SOURCE } \\
\text { OF FUNDING }\end{array}$ \\
\hline \multicolumn{4}{|l|}{ Developments Partners } \\
\hline $\begin{array}{l}\text { UN Central Emergency } \\
\text { Response Fund (CERF) }\end{array}$ & $\begin{array}{l}\text { UN global emergency response } \\
\text { pooled fund to provide financing } \\
\text { for rapid response or underfunded } \\
\text { emergencies }\end{array}$ & $\begin{array}{l}\text { - 2014/West Africa-US } \$ 15.3 \text { million } \\
\text { - 2018/DRC-US } \$ 2.8 \text { million for health } \\
\text { rapid response; US } \$ 12.3 \text { million for rapid } \\
\text { response (UN CERF 2018) }\end{array}$ & $\begin{array}{l}\text { UN-multi-donor } \\
\text { (Germany, Netherlands, } \\
\text { Norway, Sweden, UK and } \\
\text { others) }\end{array}$ \\
\hline $\begin{array}{l}\text { WHO Contingency Fund for } \\
\text { Emergencies (CFE) }\end{array}$ & $\begin{array}{l}\text { WHO emergency fund to respond } \\
\text { immediately to disease outbreaks } \\
\text { and humanitarian crises }\end{array}$ & $\begin{array}{l}\text { - 2018/DRC and neighboring countries- } \\
\text { US } \$ 4.5 \text { million } \\
\text { - } \$ 16.4 \text { million-10th Ebola outbreak }\end{array}$ & $\begin{array}{l}\text { WHO-multi-donor } \\
\text { (Australia, Denmark, } \\
\text { Germany, Japan, UK, and } \\
\text { others) }\end{array}$ \\
\hline Start Fund & $\begin{array}{l}\text { Pooled rapid response fund for } \\
\text { INGOs/NGOs to respond to small and } \\
\text { medium scale emergencies }{ }^{37}\end{array}$ & $\begin{array}{l}\text { - 10th DRC Ebola outbreak for financial } \\
\text { support to INGOs } \\
\text { - GB£250,000 to Oxfam (Alert 233) } \\
\text { - GB£350,000 Save the Children/Oxfam } \\
\text { (Alert 250); GB£300,000 ALIMA } \\
\text { - GB£300,000 disbursed to Relief } \\
\text { International for Cholera outbreak in } \\
\text { Somalia within 48h (Start Network 2016) }\end{array}$ & $\begin{array}{l}\text { Belgium, Ireland, } \\
\text { Netherlands, UK, and EC }\end{array}$ \\
\hline EU Emergency Aid Reserve & $\begin{array}{l}€ 280 \text { million Euro earmarked each } \\
\text { year as reserve fund for rapid } \\
\text { response to unforeseen events and } \\
\text { major crises in non-EU country crises } \\
\text { (priority given to humanitarian crises). } \\
\text { Funds are provided to NGOs, INGOs, } \\
\text { UN agencies, Red Cross }\end{array}$ & $\begin{array}{l}\text { - } 7.3 \text { million provided to INGOs and UN } \\
\text { agencies for 10th Ebola response }\end{array}$ & EU \\
\hline $\begin{array}{l}\text { AU Africa Risk Capacity } \\
\text { (ARC) product for O\&E }\end{array}$ & $\begin{array}{l}\text { - Pooled sovereign risk insurance } \\
\text { product for outbreaks and } \\
\text { epidemics } \\
\text { - Modelled after ARC insurance } \\
\text { - Piloting in Uganda and Guinea } \\
\text { for Ebola, Marburg, Lassa virus } \\
\text { outbreaks, and Meningitis } \\
\text { outbreaks }\end{array}$ & - Not used yet & $\begin{array}{l}\text { Rockefeller Foundation, } \\
\text { Switzerland, Africa CDC } \\
\text { (non-funding technical } \\
\text { partner), Metabiota } \\
\text { (technical partner), } \\
\text { Columbia University }\end{array}$ \\
\hline
\end{tabular}

\footnotetext{
${ }^{37}$ Fund run by 42 partners of Start Network. Disburses funds within 72 hours of an alert. Fastest, collectively owned early response mechanism in the world.
} 
BOX 5 Financial Ownership of Preparedness and Response Efforts

A number of key challenges are associated with country ownership, particularly in fragile economies. There are often inadequate domestic financial and other resources; competing developmental and political priorities; and systemic weaknesses in governance and leadership, human capital, and management systems. The economic and social shocks from extended disease outbreaks such as the Ebola epidemic in West Africa exacerbate these structural challenges.

As detailed in this report, the international community has paid considerable attention to developing financing mechanisms for outbreak response. However, financing preparedness programs through domestic and international resources have lagged far behind. If preparedness and emergency response continue to be funded largely through discrete mechanisms, this lack of attention to preparedness will persist. Some health systems programs have moved toward more integrated planning for preparedness and response through tools such as the National Action Plans for Health Security and the WHO Benchmarks for International Health Regulations Capacities. These plans enable greater country ownership in identifying priorities and directing domestic and international resources to fill the gaps.

When an outbreak hits, there often is not continuity of resources to transition from "peace time" development support to "war time" emergency response. Shorter term resource inputs are made available for acute, and often extended, response through the PEF, CFE, CERC, and other mechanisms. However, these resources were not designed to support longer term outbreak and recovery efforts, and their flexibility is being tested in the 10th DRC Ebola outbreak. As part of sustainable systems capacity, longer term response and recovery efforts need to be linked to preparedness programs. Frequently, this funding is not built into country plans or domestic budgets.

The dependence on external support during outbreaks significantly affects who drives the decision making. The entity holding the purse often has the most control. Instead of perpetuating a cycle of panic and neglect, financing for preparedness and response should be seen as a continuum of support at both the national and subnational levels. Financing initiatives for emergencies will come and go. It is the health systems programs that were there before the crisis occurred and that will help to contain the current outbreak and prevent or mitigate the next one (Figure 7).

The Global Preparedness Monitoring Board (GPMB) was established to monitor, among other areas, the state of pandemic preparedness financing. The board has documented that many of the lessons learned from the West Africa Ebola outbreak still have not translated to institutionalizing preparedness financing on the domestic or international level. Other initiatives to improve monitoring include adding a financing action package in the Global Health Security Agenda and new financing indicators in the JEE.

Nevertheless, monitoring alone will have little impact without dedicated domestic and international commitments to preparedness implementation. The World Bank REDISSE program in West Africa is one example that has substantially invested in country-led programs that support the continuum of activities from detection to response to systems recovery. Similar regional and country-level projects are coming online through the World Bank and other development partners. However, there is still a critical gap in both demand and mechanisms to fund health systems programs. Until these gaps are addressed, countries will continue to manage disease threats reactively, and priorities will continue to be set often by external stakeholders rather than by the countries.

FIGURE 7 Selected Funding Sources during Stages of an Outbreak and Recovery

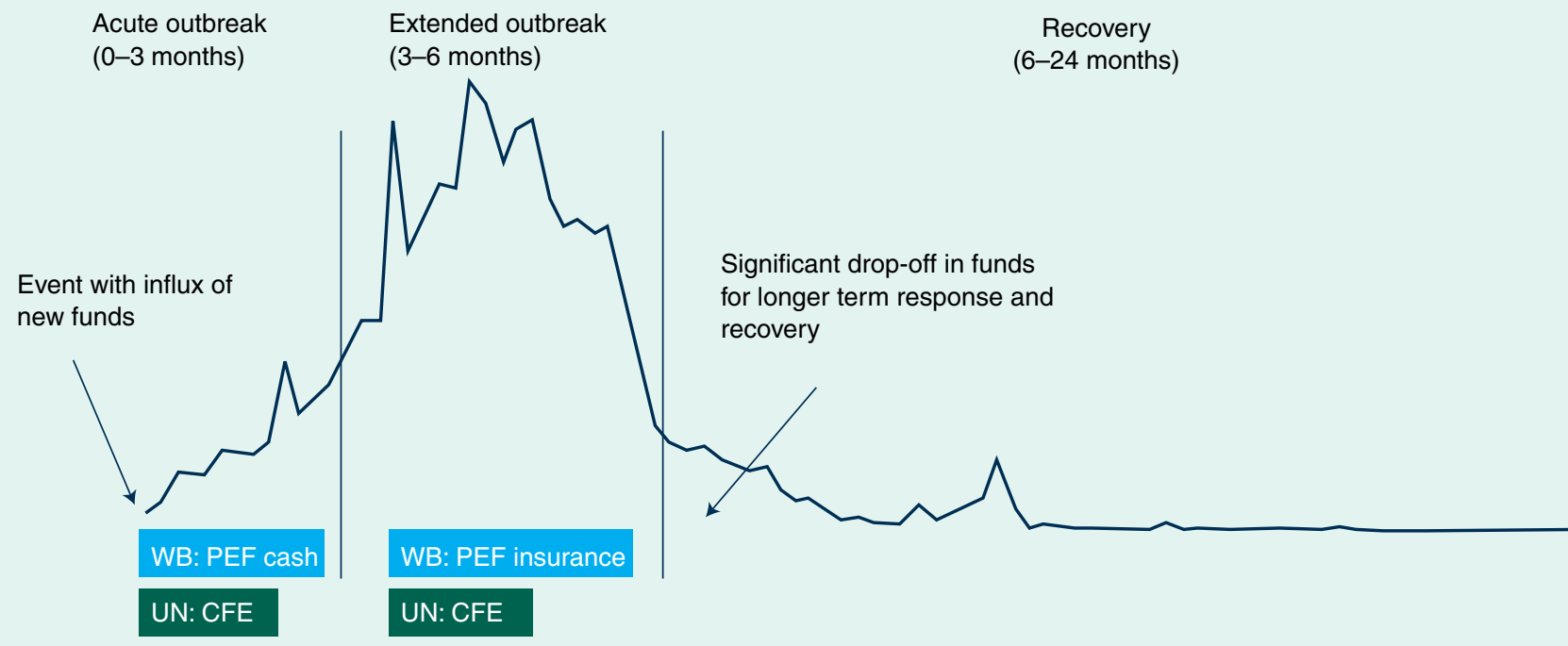

WB: CERC 


\section{WHAT HAS CHANGED IN THE EPIDEMICS OF 2018? CONTINUING CHALLENGES}

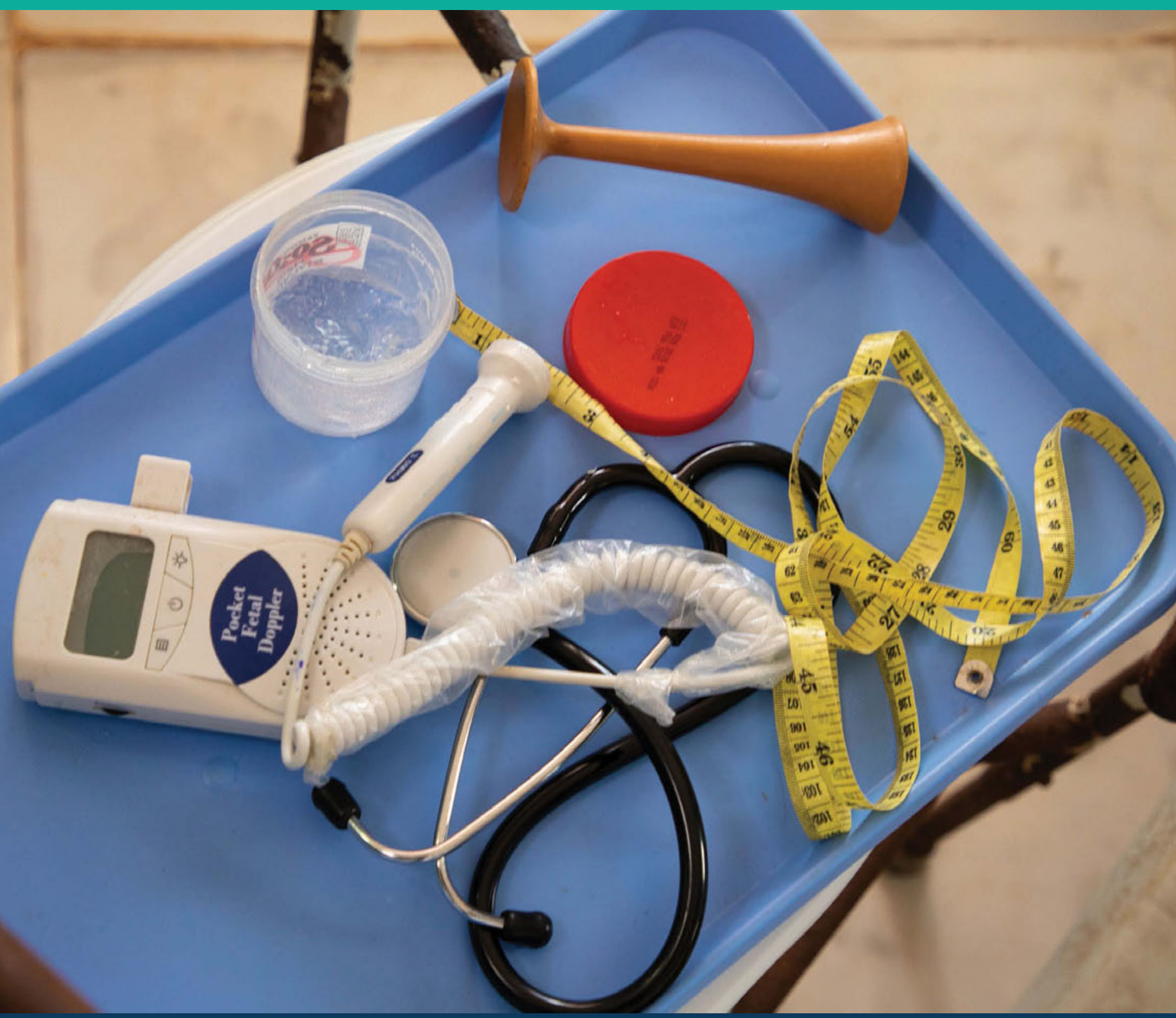


According to the Prevent Epidemics ReadyScore, based on Joint External Evaluations of 19 of the technical capacities required by the IHR, Liberia and Sierra Leone have "work to do;" whereas DRC, Guinea, and Nigeria are "not yet ready" (Figure 8). This lack of preparedness, even in countries that have demonstrated the need for these capacities, has implications for global readiness-particularly with respect to severe pandemics. Many of the interviewees for this study had a positive, but nuanced, perspective on progress. They cited significant improvements and continuing challenges in the countries that have experienced severe infectious disease epidemics as well as in the policies and financing modalities developed by external stakeholder organizations.

\section{GOVERNANCE}

\section{Positive Changes}

- Organizational reforms introduced in the wake of the West Africa Ebola crisis are helping to develop more autonomous public health institutes, such as Africa CDC, recently established as a health security asset in the region. These public health institutes include a headquarters in Addis Ababa; five regional coordinating centers (RCCs); and a National Public Health Institute or its equivalent in each country. The National Public Health Institutes, such as the Nigerian Center for Disease Control, have demonstrated strong

FIGURE 8 "Readiness" Score Based on Joint External Evaluations in Sub-Saharan Africa, 2019

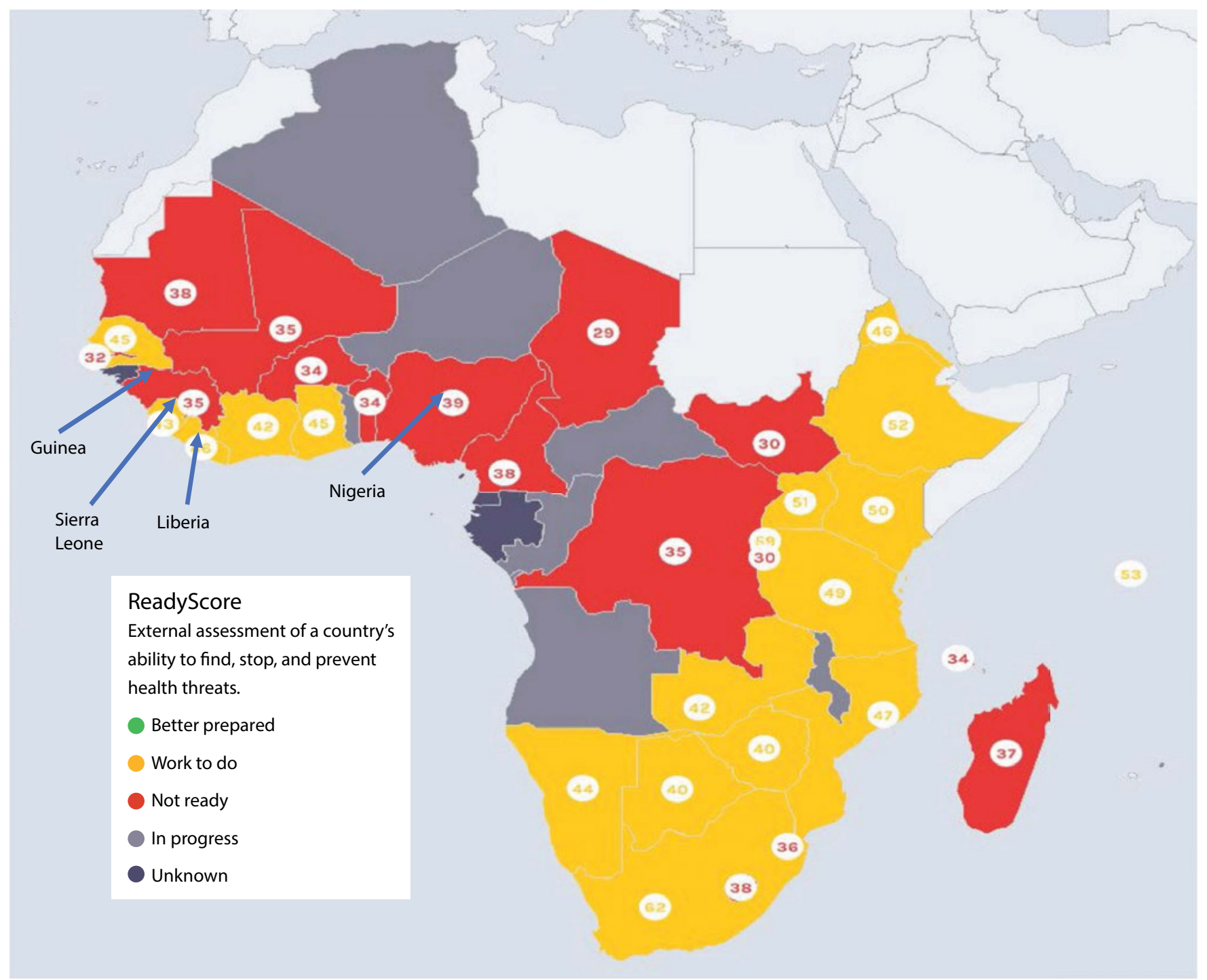

Source: preventepidemics.org. 
leadership, preparedness, and response capacity; and have overcome bureaucratic delays.

- The three countries that experienced the West Africa Ebola outbreak have since strengthened their overall emergency response. Sierra Leone has established a Directorate of Health Security and Emergencies. Liberia has instituted a One Health Steering Committee and a National Preparedness Response Committee. The role of all national militaries to support logistics, security, and treatment centers has been strengthened. Emergency Operations Centers (EOC) have been established and strengthened in all three countries.

- Reforms within WHO include, first, the establishment of the CFE, a catalytic investment tool that can deliver initial funds within hours. WHO also implemented the Health Emergencies Program (WHE), an operational branch of WHO that leads and coordinates the international outbreak response and helps countries detect and respond to health emergencies.

- WHO's introduction of the SRP, which includes costing outbreak response efforts, has increased coordination and joint planning. This tool was used to facilitate the activation of CERC to disburse emergency assistance to DRC.

- As of the writing of this report, 39 African countries have completed the JEEs, and six more are in the pipeline to do so (WHO 2019b).

- A growing number of countries have developed National Action Plans for Health Security (NAPHS), which strengthen country health system monitoring and planning capacities. Liberia, Nigeria, and Sierra Leone have completed their NAPHS, and Guinea is planning to develop one.

- The jointly developed Global Preparedness Monitoring Board (GPMB) is dedicated to strengthening policy-level coordination and trust among international and country stakeholders.

- Other development frameworks, such as the Global Health Security Agenda, which includes 50 participating countries, also strengthen the global framework to finance important dimensions of preparedness and response.
- Some countries have increased domestic financing to respond to health emergencies. The Nigeria Health Act provides for a limited contingency fund earmarked for outbreak response, and the DRC government has provided up to US\$5 million for the recent Ebola outbreaks.

\section{Continuing Challenges}

- Country leadership and response coordination remain a challenge. Donor and country priorities do not always align. Weak leadership and emergency management capacity can result in ad hoc funding, inter-donor competition, and duplication of effort.

- Effective development and implementation of the outbreak Strategic Response Plans require strong country ownership and coordination, which in turn require transparency and compliance.

- The dominant role of external implementing organizations, although helpful, needs to be complemented by stronger country ownership and oversight. Ad hoc funding contributions and lack of reporting from donors often made it difficult for national governments to determine the level and type of support that they could expect from external stakeholders.

- Effective governance of outbreaks in complex emergencies in fragile states is a major challenge that carries implications for increased conflict, distrust, and spread of disease.

- A critical gap in planning and country ownership is to adequately fund response plans that will enable the essential role of community engagement.

- Regional coordination among countries of preparedness and response planning is needed. The establishment of the Africa CDC as well as the development by the West African Health Organization (WAHO) and partner countries of the West Africa Regional Response Plan are important moves forward.

- Persuading public finance and economic authorities that investments in health security are both beneficial and cost effective is a critical step in advocating for sustainable country ownership of financing preparedness and response. 


\section{EFFICIENCY OF FINANCING}

\section{Positive Changes}

- The mobilization and disbursement of both domestic and external financing in the successful response to the 9th Ebola outbreak in DRC demonstrated clear improvements in the timeliness, flexibility, and sufficiency of new financing instruments such as WHO's CFE and the World Bank's CERC and PEF cash window.

- In Liberia, recent responses to meningitis (2017 and 2018), and yellow fever (2018) included small injections of domestic funds. Rapid access to domestic financing is a key factor in agility.

- The available menu of World Bank instruments now enables a risk-layered approach to suit the range of needs (Table 2). New World Bank health projects now routinely include a CERC and have adapted CERC guidelines to activate in public health emergencies. The trigger is based on WHO's event grading system as an alternative to WHO or government declaration of a public health emergency. WHO's grading system permits prompter access to available project funds. At least half of African countries now have provisions for CERC activation of existing project funding to respond to outbreaks.

- Efforts underway to scale up private sector support of outbreak response include the Global Private Sector Roundtable and the Nigerian Alliance for Health Emergencies, which was established in 2018.

\section{Continuing Challenges}

- Sufficient and timely domestic emergency financing remains a challenge in all the countries considered in this study. Procedural improvements are possible at each stage of preparedness and response. Availability of domestic and external financing at subnational, provincial, and local levels is particularly scarce.

- Even when funds for outbreak response are pledged early, the mechanisms leading to disbursement often are overly complex and too inflexible to meet the requirements and demands of an emergency. Ultimately, timeliness and flexible disbursement are more important than the amount pledged.
- Similarly, once funds are disbursed, agreements with implementing agencies and related procurement procedures constitute an additional layer of constraint on timely delivery of often desperately needed goods and services.

- Improving management practices, including for procurement, financial management, and accountability, is just as critical as providing the right technical support.

- "No-regrets financing" (early deployment of excessive financial and other resources) remains an organizing principle-not policy-and carries the risk of political backlash from perceived overfunding.

- Organized engagement of the private sector, including citizen communities, holds potential for both resource mobilization and implementation.

- Channeling PEF resources through governments presents potentially time-consuming procedural constraints, depending on the government's procurement and contracting capacity within the overall constraint of World Bank procedures. Low government capacity in these two areas could slow financing during emergencies, but this could be mitigated through prepositioned contracts for emergency commodities and services.

- The PEF insurance window trigger parameters and limitations on included diseases are viewed by many as too restrictive for all but catastrophic outbreaks.

\section{EFFECTIVE USE OF FINANCIAL RESOURCES}

\section{Positive Changes}

- To enable a more effective outbreak response, the World Bank regional REDISSE project strengthens overall health system absorptive capacity as well as fiduciary and management capacity. The use of private sector managers and accounting entities as cosignatories on procurement actions increased transparency and reduced misuse of response financing but also could add an additional layer of bureaucracy on moving funding quickly. 


\section{Continuing Challenges}

- Insufficient domestic resources and continued dependence on external support constrains many aspects of systems strengthening, preparedness, and response (training and retaining health workers for surveillance, contact tracing, infection prevention and control, finance and management specialists.).

- The concept of "country ownership" must refer not only to ownership of country financial resources, but also to increased decision making concerning procurement and effective use of various local resources. Stronger country engagement and capacity building to increase local procurement could reduce costs and increase efficiency.

- Hazard incentive management systems for health care workers need to be standardized with prepositioned guidance.

- Human resource capacity, while stronger than in 2014, is limited in all specialties, particularly at the subnational level.

- Country capacity for financial management and retention of qualified managers is a continuing constraint.

- Financing plans need to include community engagement aspects.

- Reporting tools need to be standardized and streamlined.

\section{FINANCING PREPAREDNESS}

Preparedness, or readiness for response, is a continuous function including prevention and early detection for containment. Investment in preparedness at the country, regional, and global levels is commonly and consistently limited due to competing budgetary and political priorities. There is no lobby or effective advocacy for preparedness, resulting in periodic mobilization of funding during a public health emergency, followed by neglect-until the next crisis hits and the cycle begins again. Both political and financial resource mobilization typically react to outbreaks that arguably could have been prevented or much reduced in impact through effective prevention, planning, and prepositioned readiness for response.

\section{Positive Changes}

- The development and activation of the new National Action Plans for Health Security (NAPHS) enable all stakeholders to subscribe to a single preparedness plan based on coordinated planning across all health security program areas.

- Initiatives including GHSA, JEE, Coalition for Epidemic Preparedness Innovations (CEPI), and WBG's REDISSE, ${ }^{38}$ with its regional approach using the One Health model, all contribute to multi-stakeholder support of preparedness.

- The systematic inclusion of the World Bank's CERC mechanism in the health portfolio and streamlining ${ }^{39}$ of the CERC implementation instrument to address eligible health emergencies significantly improve resource mobilization.

- Awareness is growing that it is more cost effective to maintain prepositioned preparedness capacity than it is to scale up response during out-of-control emergencies.

\section{Continuing Challenges}

- A global financing mechanism to incentivize investment in preparedness is required. A key challenge is to significantly increase investment in sustainable financing of preparedness at country, regional, and global levels. Mechanisms for such investment can be built into broader country development and business and global sustainability agendas and "sold" to public and private policy and financing decision makers.

- The opportunity cost of not funding preparedness is easier to appreciate against the experience of not only the US\$6 billion cost of the international response to the West Africa crisis but also the US\$53 billion cost to the society and economy of the region.

- Human capital can be the entry point to a cultural shift to investment in preparedness. The private business

\footnotetext{
${ }^{38}$ REDISSE often was very positively described by interviewees as a "game changer."

${ }^{39}$ Such as, adapting CERC triggers and positives list for greater sensitivity to health emergencies.
} 
community needs to be activated by an appeal to safeguard markets and profits (such as travel and tourism). Better and more visible metrics are needed.

- The experience gained and systems structures developed during the West Africa crisis must be strengthened to "enable a rapid and effective national response to outbreaks, while providing a global safety net for response when national efforts fail"(Coltart and others 2017). Such systems strengthening is critically dependent on establishing adequate domestic and international financing, which must give higher shared priority to both prevention and "readiness" for containment response.

- The World Bank has the opportunity to lead in developing and supporting investment in prevention and preparedness.

- Prepositioning contingencies, contracts and agreements, supplies, and human resources would streamline emergency response management operations.

\section{LIMITATIONS OF STUDY}

This report presents a qualitative analysis of the lessons learned in financing response to recent outbreaks in West and Central Africa. While the study examines many of the facets of financing outbreaks in the Africa region, it was not designed to evaluate the direct impact of specific financing modalities. Instead it describes the various systems and how they have been applied under different circumstances over time.

The data were collected retroactively from stakeholders, sometimes more than three years after the event. The team reduced the impact of recall bias by interviewing a large cross-section of stakeholders, looking for common themes between the interviews, and triangulating findings with literature reviews. The team also tried to identify interviewees who were key actors during the outbreak and not only people who were currently stationed in the countries where data collection took place.

This report is limited by the ongoing epidemic in DRC, which restricted both the fieldwork and complete analysis of lessons from the 10th Ebola outbreak there. The study focused on a subset of the overall timeline, ending at the third SRP, and was unable capture all the lessons learned due to the evolving course of the outbreak. Further work including AARs will be critical for documenting the lessons learned in financing this outbreak, including activation of PEF and CERC mechanisms. 


\section{CONCLUSION AND RECOMMMENDATIONS}
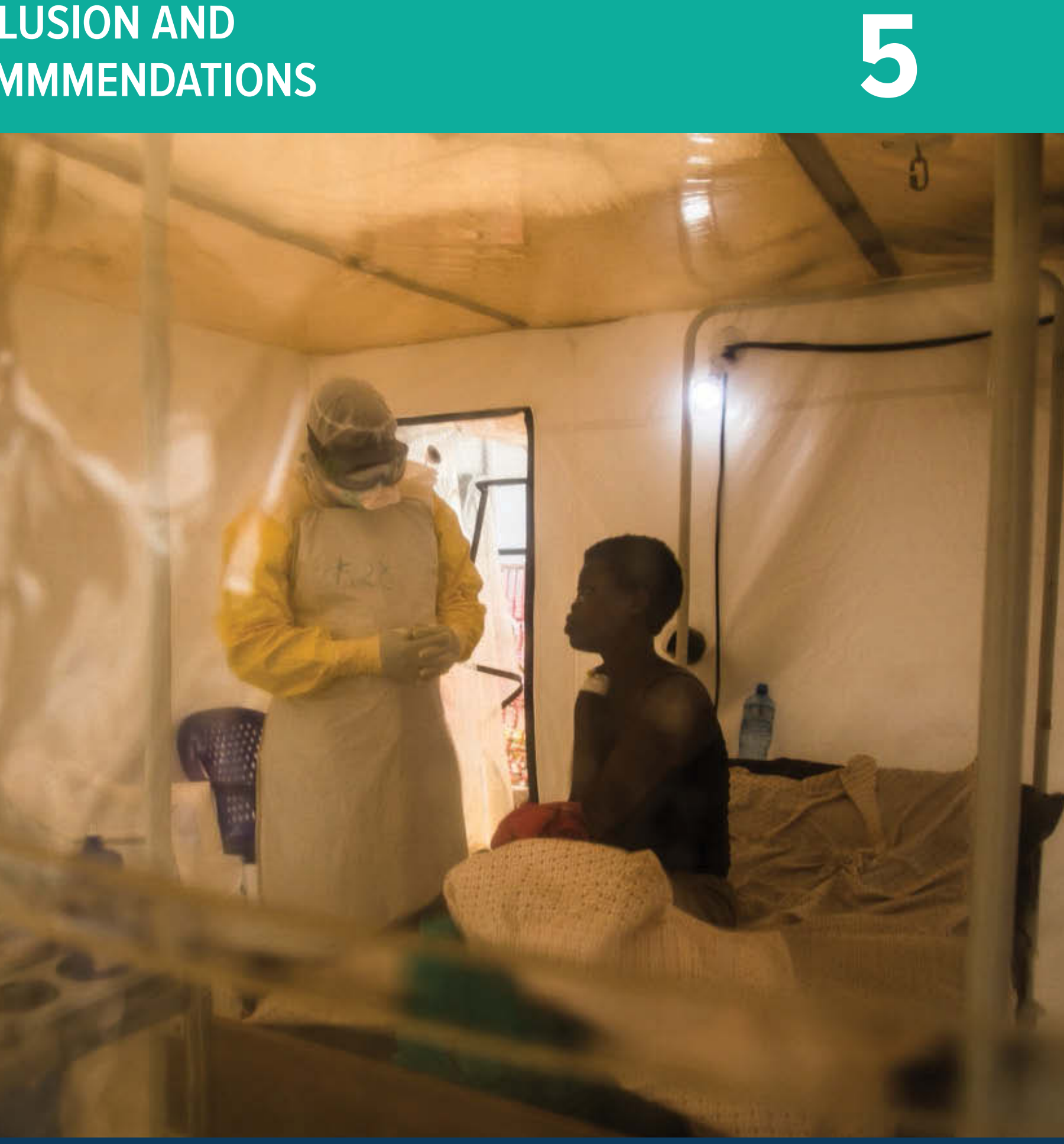
This report confirms improvements in the timeliness and efficiency of financing to contain outbreaks of infectious disease at all levels-country, regional, and global. Today, Guinea, Liberia, Sierra Leone, Nigeria (Lassa Fever outbreak, 2018), and the Democratic Republic of Congo (DRC) (9th and 10th outbreaks of Ebola) have demonstrated improved capacity for governance and operational response to outbreaks. This capacity growth, in turn, has contributed to the more efficient use of domestic and external financing.

In response to comprehensive recommendations from multiple assessments, the international development community has taken several institutional and operational steps to improve the efficiency and effectiveness of financing public health emergencies. These include the adaptation of policies and procedures that increase the agility of financing while decreasing the processing time, as well as developing new planning tools and financing mechanisms. Some examples include incorporating instruments that permit rapid access to funds into World Bank-financed projects and establishing new financing mechanisms such as the World Bank Group (WBG)'s Pandemic Emergency Financing Facility (PEF), World Health Organization (WHO)'s Contingency Fund for Emergencies (CFE), and African Union (AU)'s Africa Risk Capacity (ARC) for outbreaks. There have also been efforts to establish and strengthen institutions with global, regional, and national mandates for preparedness and response such as the WHO Health Emergencies Program (WHE), Africa Centres for Disease Control and Prevention (Africa CDC), and National Public Health Institutes (NPHIs).

Although financing routine systems to prevent and detect health threats has lagged behind initiatives to respond to emergencies, new disease surveillance and response programs have been introduced in the African subregion. One such example is the WBG's Regional Disease Surveillance Systems Enhancement (REDISSE) Program which leverages efficiency gains of scale by strengthening disease surveillance, detection, and response systems across 11 countries in West Africa.

However, there are still critical bottlenecks to overcome in improving global and national epidemic financing.

- Without a shared, continued commitment of both domestic and external financing it will be difficult to sustain gains in securing funding for outbreak response.
International development and public health agencies such as the World Bank and WHO have also demonstrated significantly greater agility in their institutional responses due, in part, to the development of several new and improved funding instruments and planning tools that enable more timely and flexible financing of outbreaks. Other national and regional entities including NPHIs and the Africa CDC are also poised to provide increased indigenous support as their institutions mature.

- Strengthening institutional management capacities will result in improved country ownership and use of funds. More streamlined planning and coordination systems including the SRPs and nationally-led EOCS have efficient resource management during outbreak response. Prepositioning agreements and contracts, streamlining processes, and providing financial management training prior to the onset of an emergency will diminish bottlenecks in receiving and moving funds quickly and efficiently, particularly when human resources are already stretched. WBG and other projects in epidemic-prone regions can be designed to include contingency instruments and legal agreements that permit financing a broad range of activities. AARs and workshops to familiarize countries and key stakeholders with financing mechanisms will improve the efficiency of financing outbreak response.

- Disease outbreaks will become increasingly common in insecure environments as transmission patterns shift, disease detection improves, and rapid response remains hindered. Agile and flexible approaches to outbreak support are even more critical in these situations and may require risk-layering of multiple funds and instruments.

- Improved transparency in budgeting, domestic and international financial commitments, and reporting will improve accountability and reduce duplication of resources. Standardized reporting tools can facilitate efforts to improve transparency and timely reporting.

- Adequate domestic investment in outbreak prevention and preparedness remains a critical challenge. The barriers to such investment stem from a combination of scarce resources and competition across sectors in prioritizing the resources available. Following 
the West Africa Ebola outbreak, although international investments have proved adequate to address acute outbreak needs, funding for preparedness has severely waned.

- Leveraging the private sector can both increase domestic resource mobilization and enhance the agility of emergency financing. Organized engagement of the private sector, including citizen communities, holds potential for rapid resource mobilization and implementation of emergency response. Collaboration with the International Finance Corporation, contingent contracting arrangements, and the use of Multilateral Investment Guarantee Agency (MIGA) guarantees could help incentivize and mobilize the private sector to respond to a crisis.
- Given its financing mandate, convening authority, and access to economic/financial policy decision makers, the World Bank is well positioned to lead a scaled-up, multi-stakeholder initiative on innovative financing to strengthen country-owned and country-led capacity for preparedness.

- In the context of the demonstrated importance of global health security, the time is also opportune for international development partners to systematically examine their overall strategies. These strategies encompass the flexibility, agility, and efficiency of existing financing tools for emergency response and building country-owned capacity for financing preparedness and emergency response. 
TABLE A1 List of Organizations Interviewed

\section{ORGANIZATION}

LOCATION/S

International Organizations

\begin{tabular}{|l|}
\hline World Bank \\
\hline World Health Organization (WHO) \\
\hline United Nations Children's Fund (UNICEF) \\
\hline United Nations Office for Project Services (UNOPS) \\
\hline United Nations Population Fund (UNFPA)
\end{tabular}

$H Q$, Guinea, Liberia, Nigeria, Sierra Leone

$H Q$, Liberia, Sierra Leone, Guinea, Nigeria

Sierra Leone, Guinea, Nigeria

Sierra Leone, Guinea

Sierra Leone

\begin{tabular}{|l|}
\hline Department for International Development (DFID) \\
\hline GIZ Germany \\
\hline Japan International Cooperation Agency (JICA) \\
\hline United States Agency for International Development (USAID), US Government \\
\hline United States Centers for Disease Control (US CDC) \\
\hline European Civil Protection and Humanitarian Aid Operations
\end{tabular}

UK, Sierra Leone/DRC

Liberia

Liberia

US, Liberia, Nigeria

US, Liberia, Sierra Leone, Nigeria

$\mathrm{DRC}$

\begin{tabular}{|l|}
\hline \multicolumn{2}{|c|}{ Local/International NGOs/Priv } \\
\hline Alliance for International Medical Action (ALIMA) \\
\hline International Federation of Red Cross (IFRC) \\
\hline Expertise France \\
\hline Riders for Health
\end{tabular}

\begin{tabular}{|l|l}
\hline Médecins Sans Frontières \\
\hline Plan International
\end{tabular}

Plan International

Jhpiego

International Rescue Committee

Clinton Health Access Initiative (CHAl)

The Carter Center

African Field Epidemiology Network (AFENET)

Irrua Specialist Teaching Hospital

GOAL

BDO

\begin{tabular}{|l|}
\hline Guinea \\
\hline Guinea, Sierra Leone \\
\hline Liberia \\
\hline Liberia \\
\hline Liberia, Sierra Leone \\
\hline Liberia \\
\hline Liberia \\
\hline Liberia \\
\hline Liberia \\
\hline Nigeria \\
\hline Nigeria \\
\hline Sierra Leone \\
\hline Sierra Leone \\
\hline Nigeria \\
\hline Sierra Leone \\
\hline Guinea \\
\hline
\end{tabular}


Audit Services, Sierra Leone. 2015a. Report on the audit of the management of Ebola funds.

Audit Services, Sierra Leone. 2015b. Report on the audit of the management of the Ebola funds by the NERC (November 2014-April 2015).

Bali, Sulzhan, Kearsley A. Stewart, and Muhammad Ali Pate. 2016. "Long shadow of fear in an epidemic: fearonomic effects of Ebola on the private sector in Nigeria." BMJ Global Health 1 (3):e000111.

Beaubien, J. 2018. “Nigeria Faces Mystifying Spike in Deadly Lassa Fever." https://www.npr.org/ sections/goatsandsoda/2018/03/19/587603462/ nigeria-faces-mystiifying-spike-in-deadly-lassa-fever

Burki, Talha. 2013. "Infectious diseases in Malian and Syrian conflicts." The Lancet Infectious Diseases 13 (4):296-297.

Cangul, Mehmet, Carlo Sdralevich, and Inderjit J. Sian. 2017. "Beating back Ebola: nimble action on the economic front was key to overcoming the health crisis." Finance and Development 54 (2):54-57.

CDC. 2015. "Ebola Report: Timeline." https://www.cdc.gov/ about/ebola/timeline.html

CDC. 2016. Cost of 2014 Ebola Epidemic.

Coltart, Cordelia E. M., Benjamin Lindsey, Isaac Ghinai, Anne M. Johnson, and David L. Heymann. 2017. "The Ebola outbreak, 2013-2016: old lessons for new epidemics." Philosophical Transactions of the Royal Society B: Biological Sciences 372 (1721):20160297.

Commons, House of. 2016. UK lessons from Ebola outbreak.

Culver, Amanda, Roger Rochat, and Susan T. Cookson. 2017.

"Public health implications of complex emergencies and natural disasters." Conflict Health 11 (1):32.

Cummins, J. David, and Olivier Mahul. 2008. Catastrophe risk financing in developing countries: Principles for public intervention. The World Bank.

DRC Ministry of Health. 2018a. National Plan for the Response to the Ebola Virus Disease Epidemic in North Kivu Province.

DRC Ministry of Health. 2018b. "Strategic Response for Ebola in DRC (SRP II)."
DuBois, Marc, Caitlin Wake, Scarlett Sturridge, and Christina Bennett. 2015. The Ebola response in West Africa: exposing the politics and culture of international aid. Overseas Development Institute.

Elmahdawy, Mahmoud, Gihan H. Elsisi, Joao Carapinha, Mohamed Lamorde, Abdulrazaq Habib, Peter AgyieBaffour, Redouane Soualmi, Samah Ragab, Anthony W. Udezi, and Cyril Usifoh. 2017. "Ebola virus epidemic in West Africa: global health economic challenges, lessons learned, and policy recommendations." Value in Health (regional issue) 13:67-70.

Elston, J. W. T., C. Cartwright, P. Ndumbi, and J. Wright. 2017. "The health impact of the 2014-15 Ebola outbreak." Public Health 143:60-70.

Evans, David K., Markus Goldstein, and Anna Popova. 2015. "Health-care worker mortality and the legacy of the Ebola epidemic." The Lancet Global Health 3 (8):e439-e440.

Fanning, Emma. 2018. "The Ebola Outbreak in DRC: Strengthening the response."

Federspiel, Frederik, and Mohammad Ali. 2018. "The cholera outbreak in Yemen: lessons learned and way forward." BMC Public Health 18 (1):1338.

Fielding, J., T. Allen, B. Chu, J. Galdo, and H. Gayle. 2016. Report of the Independent Panel on the US Department of Health and Human Services (HHS) Ebola Response. In Washington, DC: United States Department of Health Human Services, Office of the Assistant Secretary for Preparedness Response.

Flessa, Steffen, and Michael Marx. 2016. Ebola fever epidemic 2014: a call for sustainable health and development policies. Springer.

Frost L., Pratt B. A. 2015. The World Bank's Rapid Response to the 2014 Ebola Outbreak in West Africa.

Global Ebola Response. 2014. Ebola Outbreak-Updated overview of needs and equirements for January-June 2015.

Global Ebola Response. 2019. “Timeline.” https:// ebolaresponse.un.org/timeline 
Gostin, Lawrence O., and Eric A. Friedman. 2015. "A retrospective and prospective analysis of the west African Ebola virus disease epidemic: robust national health systems at the foundation and an empowered WHO at the apex." The Lancet 385 (9980):1902-1909.

Gostin, Lawrence O., Matthew M. Kavanagh, and Elizabeth Cameron. 2019. "Ebola and War in the Democratic Republic of Congo: Avoiding Failure and Thinking Ahead." JAMA 321 (3):243-244.

Gostin, Lawrence O., Carmen C. Mundaca-Shah, and Patrick W. Kelley. 2016. "Neglected dimensions of global security: the global health risk framework commission." JAMA 315 (14):1451-1452.

Gostin, Lawrence O., Oyewale Tomori, Suwit Wibulpolprasert, Ashish K. Jha, Julio Frenk, Suerie Moon, Joy Phumaphi, Peter Piot, Barbara Stocking, and Victor J. Dzau. 2016. "Toward a common secure future: four global commissions in the wake of Ebola." PLoS Medicine 13 (5):e1002042.

Govindaraj, Ramesh, Christopher H. Herbst, and John Paul Clark. 2017. Strengthening Post-Ebola Health Systems: From Response to Resilience in Guinea, Liberia, and Sierra Leone. World Bank Publications.

Graves, Casey M., Annie Haakenstad, and Joseph L. Dieleman. 2015. "Tracking development assistance for health to fragile states: 2005-2011." Globalization Health 11 (1):12.

Grépin, K. 2015. "International donations to the Ebola virus outbreak: too little, too late?" BMJ 350:h376.

Harman, Sophie. 2014. "Ebola and the politics of a global health crisis." E-International Relations 36.

Heymann, David L., Lincoln Chen, Keizo Takemi, David P. Fidler, Jordan W. Tappero, Mathew J. Thomas, Thomas A. Kenyon, Thomas R. Frieden, Derek Yach, and Sania Nishtar. 2015. "Global health security: the wider lessons from the west African Ebola virus disease epidemic." The Lancet 385 (9980):1884-1901.

Huber, Caroline, Lyn Finelli, and Warren Stevens. 2018. "The economic and social burden of the 2014 Ebola outbreak in West Africa." The Journal of Infectious Diseases 218 (suppl_5):S698-S704.

IEG. 2013. Responding to Global Public Bads: Learning from Evaluation of the World Bank Experience with Avian Influenza 2006-13. World Bank.
Jeggo, Martyn, and John S. Mackenzie. 2014. “Defining the future of one health." One Health: People, Animals, and the Environment:255.

Kikwete, Jakaya, Celso Amorim, Micheline Calmy-Rey, Marty Natalegawa, Joy Phumaphi, and Rajiv Shah. 2016. Protecting Humanity from Future Health Crises: Report of the High-level Panel on the Global Response to Health Crises. New York: United Nations. Google Scholar.

Loewenson, R., A. Papamichail, and I. Ayagah. 2015. "African responses to the 2014/5 Ebola Virus Disease Epidemic." EQUINET.

Lupel, Adam, and Michael Snyder. 2017. "The Mission to Stop Ebola: Lessons for UN Crisis Response."

Moon, Suerie, Jennifer Leigh, Liana Woskie, Francesco Checchi, Victor Dzau, Mosoka Fallah, Gabrielle Fitzgerald, Laurie Garrett, Lawrence Gostin, and David L. Heymann. 2017. "Post-Ebola reforms: ample analysis, inadequate action." BMJ Global Health 356:j280.

Moon, Suerie, Devi Sridhar, Muhammad A. Pate, Ashish K. Jha, Chelsea Clinton, Sophie Delaunay, Valnora Edwin, Mosoka Fallah, David P. Fidler, and Laurie Garrett. 2015. "Will Ebola change the game? Ten essential reforms before the next pandemic. The report of the HarvardLSHTM Independent Panel on the Global Response to Ebola." The Lancet 386 (10009):2204-2221.

Moore, Melinda, Bill Gelfeld, Adeyemi Okunogbe, and Paul Christopher. 2016. Identifying future disease hot spots: Infectious Disease Vulnerability Index. Rand Corporation. Munster, Vincent J., Daniel G. Bausch, Emmie de Wit, Robert Fischer, Gary Kobinger, César Muñoz-Fontela, Sarah H. Olson, Stephanie N. Seifert, Armand Sprecher, Francine Ntoumi, Moses Massaquoi, and Jean-Vivien Mombouli. New England Journal of Medicine Ntoumi. 2018. "Outbreaks in a rapidly changing Central Africa-lessons from Ebola." 379 (13):1198-1201.

NCDC. 2018a. "Honourable Minister of Health Announces End of Emergency Phase of Nigeria's Lassa Fever Outbreak." May 11, 2018. https://ncdc.gov.ng/ news/142/honourable-minister-of-health-announcesend-of-emergency-phase-of-nigeria\%5C\%27s-lassafever-outbreak

NCDC. 2018b. Lassa Fever After Action Review.

NCDC. 2018c. Reported Cluster of Lassa Fever Among Health Care Workers in Ebonyi State. 
NCDC. 2018d. Weekly Epidemiology Report (49).

OECD. 2018. States of Fragility 2018.

Office of the UN Special Envoy on Ebola. 2014. Resources for Results I.

Office of the UN Special Envoy on Ebola. 2016. Resources for Results V (September 1, 2014 to October 31, 2015).

Oleribe, Obinna O., Babatunde L. Salako, M. Mourtalla Ka, Albert Akpalu, Mairi McConnochie, Matthew Foster, and Simon D. Taylor-Robinson. 2015. “Ebola virus disease epidemic in West Africa: lessons learned and issues arising from West African countries." Clinical Medicine 15 (1):54-57.

Ovadiya, Mirey, Adea Kryeziu, Syeda Masood, and Eric Zapatero Larrio. 2015. Social protection in fragile and conflict-affected countries: trends and challenges. The World Bank.

Parpia, Alyssa S., Martial L. Ndeffo-Mbah, Natasha S. Wenzel, and Alison P. Galvani. 2016. "Effects of response to 2014-2015 Ebola outbreak on deaths from malaria, HIV/ AIDS, and tuberculosis, West Africa." Emerging Infectious Diseases 22 (3):433.

Pring, Coralie. 2015. People and corruption: Africa survey 2015: Transparency International.

Ravi, Sanjana J., Michael R. Snyder, and Caitlin Rivers. 2019.

"Review of international efforts to strengthen the global outbreak response system since the 2014-16 West Africa Ebola Epidemic." Health Policy Planning.

Rey, C. 2018. Ebola Recovery and Reconstruction Trust Fund Evaluation.

Reynolds, C. 2015. “World Bank Group's support to the Ebola virus response effort" BMJ 350:h1283.

Ross, Emma, Gita Honwana Welch, and Philip Angelides. 2017. "Sierra Leone's Response to the Ebola Outbreak." Chatham House Report.

Spengler, Jessica R., Elizabeth D. Ervin, Jonathan S. Towner, Pierre E. Rollin, and Stuart T. Nichol. 2016. "Perspectives on West Africa Ebola virus disease outbreak, 2013-2016." Emerging Infectious Diseases 22 (6):956.

Spiegel, Paul B., Phuoc Le, Mija-Tesse Ververs, and Peter Salama. 2007. "Occurrence and overlap of natural disasters, complex emergencies and epidemics during the past decade (1995-2004)." Conflict Health Policy 1 $(1): 2$.
Start Network. 2016. "Alert 087." https://startnetwork.org/ start-fund/alerts/087-somalia-cholera\#ig

UN CERF. 2018. "CERF Allocations-DRC."

UNMPTF. 2017. UN Ebola Response Multi-Partner Trust Fund Lessons Learned Exercise.

USAID. 2016. "West Africa-Ebola outbreak factsheet." https://www.usaid.gov/sites/default/files/ documents/1866/west_africa_fs07_01-21-2016.pdf

USAID, OFDA. 2018. "Evaluation of Ebola Virus Disease Response in West Africa 2014-2016: Objective 4, Coordination of the Response."

WBG. 2010. Fifth Global Progress Report on Avian and Pandemic Influenza-A Framework for Sustaining Momentum.

WBG. 2018. "Global Crisis Risk Platform."

WHO. 2014. "WHO statement on the meeting of the International Health Regulations Emergency Committee concerning the international spread of wild poliovirus." 5:2014.

WHO. 2015a. "Report of the Ebola Interim Assessment Panel."

WHO. 2015b. WHO leadership statement on the Ebola response and WHO reforms (corrected text). Geneva.

WHO. 2016. "Ebola Situation Reports | Ebola." http://apps .who.int/ebola/ebola-situation-reports

WHO. 2017. Emergency Response Framework (ERF).

WHO. 2018a. "CFE Allocations (December 19, 2018)."

WHO. 2018b. Situation report 17: declaration of the end of the Ebola outbreak in Équateur Province.

WHO. 2019a. DRC Ebola External Situation Report 27. December 5, 2019.

WHO. 2019b. "JEE Dashboard."

WHO AFRO. 2018. Weekly report on outbreaks and other health emergencies (Week 7, 2018).

Wise, Paul H., and Michele Barry. 2017. "Civil War \& the Global Threat of Pandemics." Dædalus 146 (4):71-84.

Witter, Sophie. 2012. "Health financing in fragile and postconflict states: what do we know and what are the gaps?" Social Science Medicine 75 (12):2370-2377.

World Bank. 2011. World development report 2011: Conflict, security, and development. World Bank.

World Bank. 2014a. Project Appraisal Document, Ebola Emergency Response Project. 
World Bank. 2014b. Project Paper on Proposed additional grants from IDA CRW for the EERP.

World Bank. 2015a. ERRTF FAQs.

World Bank. 2015b. Update on the economic impact of the 2014-15 Ebola epidemic on Liberia, Sierra Leone, and Guinea.

World Bank. 2017a. "From panic and neglect to investing in health security: financing pandemic preparedness at a national level."

World Bank. 2018. "ERRTF Annual Report: From crisis response to recovery and resilience."
World Bank, UN. 2017b. Pathways for Peace: Inclusive Approaches to Preventing Violent Conflict.

Yamey, Gavin, Marco Schäferhoff, Ole Kristian Aars, Barry Bloom, Dennis Carroll, Mukesh Chawla, Victor Dzau, Ricardo Echalar, Indermit Singh Gill, and Tore Godal. 2017. "Financing of international collective action for epidemic and pandemic preparedness." The Lancet Global Health 5 (8):e742-e744. 
(4) WORLD BANK GROUP 